\title{
Comparative Medical Ethnobotany of the Senegalese Community Living in Turin (Northwestern Italy) and in Adeane (Southern Senegal)
}

\author{
Rachele Ellena, ${ }^{1}$ Cassandra L. Quave, ${ }^{2}$ and Andrea Pieroni ${ }^{1}$ \\ ${ }^{1}$ University of Gastronomic Sciences, Piazza Vittorio Emanuele 9, Pollenzo, 12060 Bra, Italy \\ ${ }^{2}$ Center for the Study of Human Health, Emory University, 550 Asbury Circle, Candler Library 107, Atlanta, GA 30322, USA
}

Correspondence should be addressed to Andrea Pieroni, a.pieroni@unisg.it

Received 20 February 2012; Accepted 26 March 2012

Academic Editor: Manuel Pardo-de-Santayana

Copyright () 2012 Rachele Ellena et al. This is an open access article distributed under the Creative Commons Attribution License, which permits unrestricted use, distribution, and reproduction in any medium, provided the original work is properly cited.

A medico-ethnobotanical survey was conducted among the Senegalese migrant communities of Turin (Piedmont, NW Italy) and their peers living in Adeane (Casamance, Southern Senegal), both among healers and laypeople. Through 27 in-depth interviews, 71 medicinal plant taxa were recorded and identified in Adeane and 41 in Turin, for a total of 315 different folk remedies recorded in Senegal and 62 in Turin. The large majority of the medicinal plants recorded among Senegalese migrants in Turin were also used in their country of origin. These findings demonstrate the resilience of home remedies among migrants and consequently the role they should have in shaping public health policies devoted to migrant groups in Western Countries, which seek to seriously take into account culturally sensitive approaches, that is, emic health-seeking strategies.

\section{Introduction}

In the last decade, the ethnobotany of migrant populations, especially in Western countries, has become the focus of a number of studies, which have investigated the trajectories of change of Traditional Medicines (TMs) and especially Traditional Knowledge (TK) concerning medicinal plants. Moreover, such studies have made progress in gaining a better understanding of newcomers' health-seeking strategies. These data are crucial in the implementation of culturally sensitive approaches in public health and nutritional policies in the host countries and/or to improve phytopharmacovigilance [1-5].

In particular, in Europe, the ethnobotanical knowledge of various migrant groups has been studied in different (mainly urban) contexts: Turkish and Russian migrants in Germany $[6,7]$; Thai women in Sweden [8]; Surinamese migrants in The Netherlands [9, 10]; South-Asians [11-14] and Andeans in England [15-17]. From these previous studies, three key findings have emerged so far.

(i) Newcomers' TK and related domestic practices may show various degrees of resilience (i.e., the attitude to recover from the changes, which originate from the displacement).

(ii) The resilience is highly dependent on practical circumstances (distance between the home and the host countries, corresponding to possibilities of frequent travel), but also on complex cultural exchanges ongoing between the diasporas and the autochthonous and/or other migrant populations. For example, factors such as (1) the occurrence of relevant transnational social and trade networks between the migrants and their home country, (2) the availability of traditional practitioners and/or herbs and food plant items in food shops in the host country, (3) identity-bound perceptions in relation to specific botanicals (which may be considered culturally important), (4) laws in place in the host countries allowing or tolerating the occurrence of non-autochthonous food/medicinal plants, and (5) multicultural approaches in the institutionalised public health frameworks of the host country, all play crucial roles in determining the resilience and sustainability of these TM practices in the migrants' host country. 
(iii) The aforementioned cultural negotiations that impact TK resilience are rapidly changing on both temporal and spatial scales, and even the "representation" of plants and remedies related to "traditions" is in a state of flux among generations over time.

In Italy, no ethnobotanical study has addressed these specific issues thus far, despite the fact that the country has faced tremendous changes in its social structure over the last two decades. In fact, these changes are due in large part to the arrival of a significant number of young and middle-aged migrants from Africa and especially Eastern Europe (most notably, Romanians and Albanians). Nowadays, it is estimated that five million migrants live in Italy, with an increase of three million in the last ten years [18]. The large majority of migrants live in the Central-Northern regions of the country; one-fifth of which are Romanians, followed by Albanians and Moroccans. The Senegalese are quantitatively the 17th largest migrant community in Italy, but they represent the biggest "black" African community in the country, encompassing approximately 73,000 members. Moreover, this community is also historically one of the most important migrant groups in Italy, as it formed a significant presence already in the 1980's [18].

Recent sociological studies have pointed out the existence of a Senegalese transmigrant movement made of people who are regular "comers and goers" between Africa and Europe and that their perception of a successful return is still associated-in contrast with other African communitieswith permanent return to their homeland. This final aim is, however, generally compromised with aspirations of economic advancement and family obligations $[19,20]$. Most of the earnings of Senegalese migrants are used for investment in housing in their home country, significantly altering the landscape of local cities [21].

Despite the fact that a study has well demonstrated the link between depression and rapid changes in the social organisation among Senegalese migrants [22], a fair public debate on culturally sensitive approaches in transcultural health policies is still lacking in Italy. This could be due to the state of political discourse in Italy, which has been highly influenced over the last years by instances of xenophobia, and which has subsequently affected several political actors and policy makers [23-27].

The aims of this study were to record uses of natural remedies (including food preparations perceived as "healthy") among the Senegalese community of Turin (Northern Italy) and in their country of origin, to compare these two ethnobotanies and to consequently formulate considerations on how TK changed or is changing following displacement of Senegalese citizens.

\section{Material and Methods}

\subsection{The Study Area and Fieldwork}

2.1.1. Turin, Italy. Turin (approx. 900,000 inhabitants, Piedmont, NW Italy, Figure 1) hosts an important Senegalese migrant community counting approx. 1,200 members

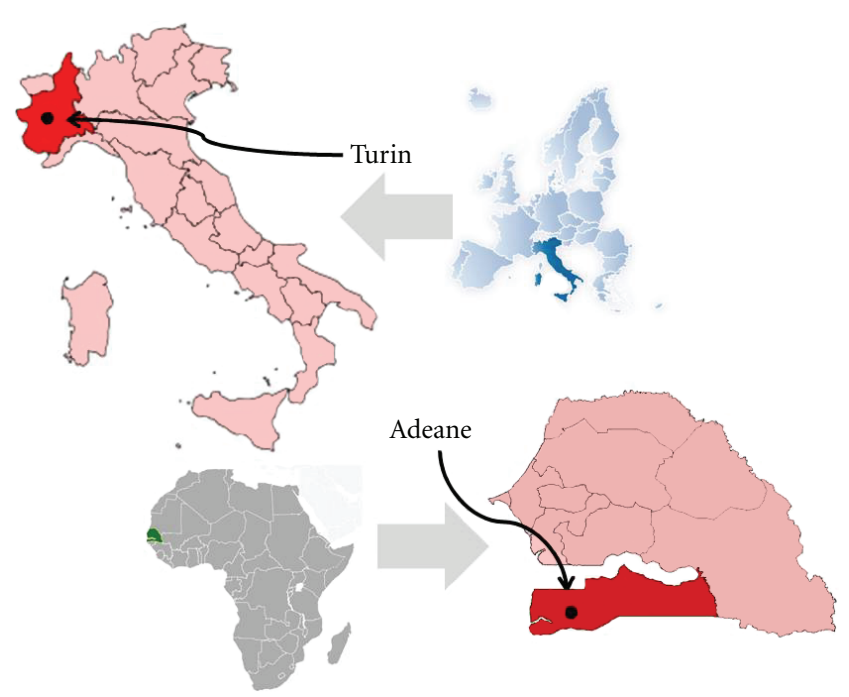

Figure 1: Location of the study sites.

(2004) [28]. The most significant influx of Senegalese in Turin only began at the end of 1980s. At that time, young males migrated to Italy from various areas of the Senegalese countryside and especially from those areas which were badly affected by the great drought of the 1970s. Traditionally, families gave their fourth or fifth child away to the Islamic brotherhood of believers for instruction in the faith and to work for the order, mainly engaging in agricultural activities. With the advance of desertification, however, the practice of agriculture was increasingly difficult and, as a consequence, the order allowed young people to move abroad to work in industry and services [28].

It was therefore a progressive flow, and not a mass migration, that characterized the Senegalese emigration to Italy. As often happens, the journey for many has been fragmented at various stages due to issues such as the search of a visa or other means of entry into the country. However, in Turin, the first arrivals had no intention of staying, since their aim was to work hard for a few years and return the home country. With time, however, things have changed, resulting in more stable settlements in the Italian landscape [28].

2.1.2. Adeane, Senegal. Adeane is a town of 9,000 inhabitants, located an hour's drive from Ziguinchor, the largest urban centre in the region of Casamance, Southern Senegal (Figure 1). The climate in Casamance is the most humid of the country and subtropical forests prevail in the landscape. The abundance of rain in the Casamance permits the cultivation of a wide variety of crops.

The Casamance is inhabited mainly by the Jola ethnic group (Diola, in the French transliteration), which constitute approximately $60 \%$ of the population. Those of the Wolof ethnic group, which represent the ethnic majority in Senegal, constitute only $5 \%$ in the Casamance region. The largest portion of the Casamance inhabitants identifies their religious beliefs with Islam, while $17 \%$ are Catholics. This isolation has determined a strong regional identity and thus the culture 
of its people as well as its environmental heritage has been well preserved for a long time. The regional economy is based in part on tourism, especially along the coast and on the sale of crops like rice, peanuts, and millet.

2.1.3. The Fieldwork. Fieldwork was conducted over a period of one month (November 2010) in Turin and over a period of a second month (December 2010) in Adeane (Casamance, Southern Senegal). Turin was selected as a field site because it is the home of a vibrant Senegalese community, while the area of Casamance in Senegal was chosen because it is considered the most biological and cultural diverse region of the country, as well as the most conservative in terms of folk practices.

Participants in Turin were selected using snowball techniques among the first generation of Senegalese migrants ( $n=8$, all males), while in Casamance the same technique was used to select "laypeople" ( $n=15,7$ females and 8 males). Additionally, in Adeane 4 healers $(3$ males and 1 female) were also interviewed. Prior Informed Consent (PIC) was obtained verbally before commencing each interview. Ethical guidelines followed the International Society of Ethnobiology Code of Ethics [29].

Questions concerning the use of medicinal and/or food plants were asked via a previous free listing of pathologies and related use of "home remedies." For each named item, the field researcher (RE) asked for exact details of how the home medicine/food was prepared and its folk medical/food use. Interviews were conducted in Italian in Turin and in French in Casamance.

In Casamance, the named plant items were collected, when available, photographed, dried, identified by a local plant taxonomist (Professor Amadou Tidiane, Department of Agricultural Studies, University of Ziguinchor, Senegal) and via the West African plants photo database [30], and deposited at the Herbarium of the University of Gastronomic Sciences, Pollenzo, Italy. The nomenclature follows IPNI [31], with family assignments following the current Angiosperm Phylogeny Group III recommendations [32, 33].

2.2. Data Analysis. The ethnobotanical data collected from Turin and Adeane were compared with each other. Moreover, the ethnobotanical data were compared with the preexisting literature on Senegalese TM and the traditional pharmacopoeia of Senegal [34-36].

\section{Results and Discussion}

3.1. The Medical Ethnobotany of the Senegalese Migrants in Turin. Table 1 reports all medicinal plants quoted by the Senegalese migrants in Turin. In total, 47 folk taxa were recorded as medicinally used in Turin; 41 of these have been botanically identified. Of these remedies, only a few (eight) could be considered food medicines, thus contradicting what previous studies among migrants medical ethnobotanies have found $[6,13,17]$. This may be due to the fact that regular provision of African vegetables and other fresh food ingredients is scarce in Turin, where generally only dried

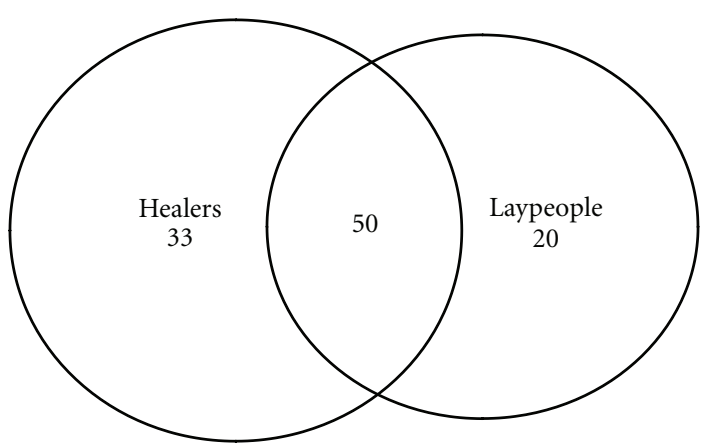

FIgURE 2: Overlap between the folk medicinal taxa quoted by healers and laypeople in Adeane.

spices and medicinal plants are imported. Another explanation may be that the Senegalese migrant community in Turin is mainly represented by males, who-in contrast to women - are not holders of culinary knowledge and therefore they do not generally have experience in managing healthcare via the diet within the domestic domain.

All remedies quoted in Turin are generally bought in small ethnic food shops and mini-supermarkets located in city centre and managed by African and/or Chinese migrant entrepreneurs. A few of the most quoted taxa (Acacia, Adansonia, Guiera, Hibiscus) are well-known African medicinal plants, which are however lacking in the Western TM pharmacopoeia.

3.2. The Medical Ethnobotany of Adeane in Senegal. Table 2 reports all medicinal plants quoted in Adeane. In total, 71 species, representing 31 botanical families, were recorded as components to TMs in Adeane. However, although the large majority of recorded medicinal taxa were found in the reviews of the Senegalese TM [34-36], only a minority $(<40 \%)$ of the actual medicinal plant uses are reported in the considered literature. This confirms the highly dynamic character of the home medicines in rural Africa and highlights the urgent need for inventorying folk plant uses beyond those that are cited in the "standardized" TM reviews.

Documentation and evaluation of these home remedies are very important, since they represent a means of primary healthcare for most. Figure 2 illustrates the overlaps between the plants quoted in Casamance by healers and laypeople. Laypeople's knowledge of medical plants is quite remarkable and confirms that the actual practice of household phytotherapy in Africa is much broader of what we sometimes label as "Traditional Medicine," which is generally restricted to the knowledge, practices, and beliefs of healers. Moreover, despite living in the same village, while healers and laypeople use in large part the same medicinal plants (Figure 2), the actual plant reports (plant-based preparations used for a given health problem) are highly divergent (Figure 3 ). These findings confirm a remarkable "internal" variability of the African medical ethnobotanies, as a recent study in rural Mozambique also pointed out [37]. 


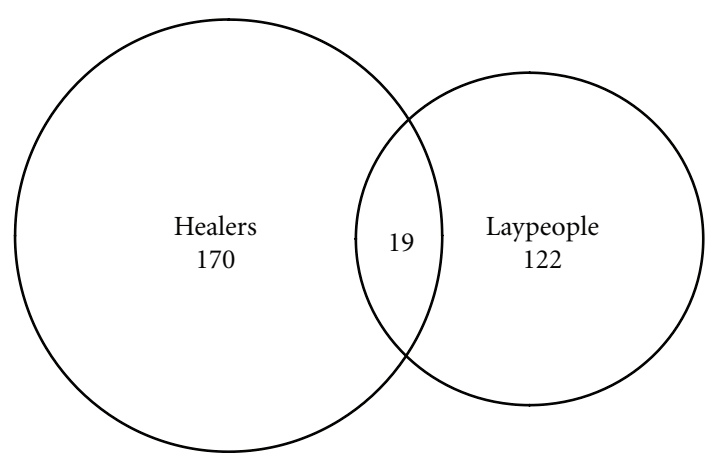

FIGURE 3: Overlap between the medicinal plant reports quoted by healers and laypeople in Adeane (a single medicinal plant report is defined as "a given taxon $x$, prepared as $y$, used for $z$ ").

3.3. Comparison between the Senegalese Medical Ethnobotanies of Turin and Adeane. A comparison between the laypeople's medical ethnobotany in Turin and Adeane demonstrates that Senegalese in Senegal use more plants than Senegalese in Turin (Figure 4). This may be due to an objective difficulty to acquire all African plants used in country of origin in the new cultural environment in Italy and also to an adaptation process. Migrants moved in fact from their original rural areas in Senegal (where the use of herbal TMs is widespread) to urban environments in Europe, where practices of use of medicinal plants are only available within the context of Western modern herbalism and phytotherapy: Senegalese TM practitioners seem in fact not to be present in Turin. Moreover, migrants from Senegal in Turin also generally rely on Western pharmaceuticals.

However, the large majority of the medicinal botanical genera recorded in Turin are also used in the country of origin, thus confirming some resilience of original practices following displacement into another landscape. The fact that a few other genera (twelve) have been quoted instead by migrants in Turin, but not in Adeane, could possibly be explained in two ways.

(i) Senegalese migrants living in Turin did not all come from the southern part of Senegal. For instance, a few of them may have brought plant uses to Turin that are unknown in the folk medicine of Southern Senegal.

(ii) A few genera recorded quoted in Turin (i.e., Hibiscus, Zingiber) may represent the result of cross-cultural exchanges of TMs with other migrant populations in Turin, especially with the North African migrants, who also share the same religion, and with members of the Chinese migrant community who own ethnic food markets in Turin.

Out of this comparative study, a few plant families have emerged as being integral to the TM practices of the Senegalese study participants both in Turin and Adeane. In particular, a great variety of Fabaceae species were quoted as having medicinal applications in Turin (7 species) and Adeane (15 species). The second and third most represented botanical families amongst the Turin participants were Combretaceae and Malvaceae, with 5 and 3 species quoted, respect-

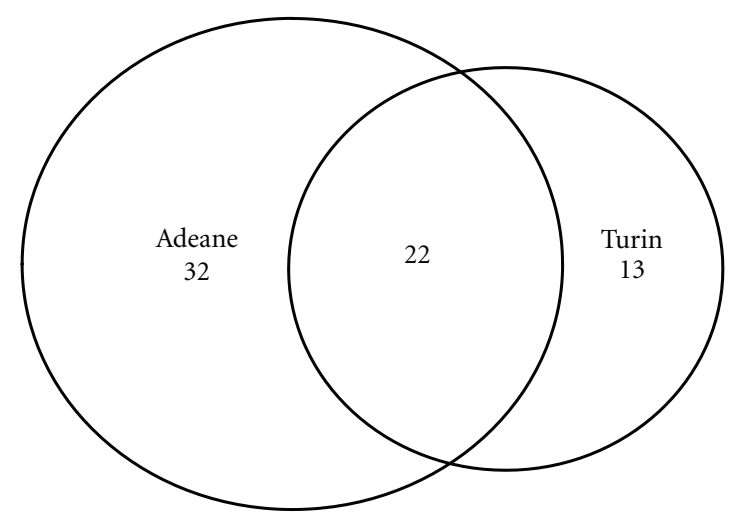

Figure 4: Overlap between the botanical genera quoted as medicinally used in Turin and Adeane (by laypeople).

fully. In Adeane, however, Malvaceae was the second most quoted family ( 5 species), followed by Apocynaceae and Solanaceae (4 species each), and then Combretaceae, Myrtaceae, Euphorbiaceae, and Meliaceae, represented by 3 species each.

Interestingly, despite the presence of a thriving Senegalese community in the north Italian landscape for more than 30 years, relatively few Italian medicinal plants appear to have been incorporated into the TM practices of this group. Take, for example, the notable lack of incorporation of several European mints (Lamiaceae) in the TM practices of the Senegalese in Turin. Various Lamiaceae species, such as mint, basil, peppermint, rosemary, thyme, horehound, and oregano, grow in the wild and/or are cultivated in the Italian countryside and the use of such species for medicinal purposes dates back to more than 2,000 years ago in this region, as evidenced by their presence in the ancient textbooks of the Mediterranean Materia Medica [38]. Moreover, the important use of Lamiaceae species as medicinal plants is crucial also in the medico-ethnobotanical literature of Piedmont ([39] and references therein). The conspicuous absence of Lamiaceae uses in the Senegalese migrant community is maybe reflective of their isolation from the Italian environmental and medical landscape, which may have been further enhanced by the characteristic male composition of the Senegalese community in Italy.

\section{Conclusion}

Our study illustrates that the herbal medicines used by the Senegalese in Turin are very different from those of the Italian herbal landscape and that the migrant population in Turin is instead reliant on the undependable trade and movement of plant materials from their homeland to ethnic markets in the city. This shows maybe a scarce integration of this African community into the host society.

Moreover, the access and availability of important original medicines, especially medicinal foods, are greatly diminished in Turin, creating a significant disruption in their TM system. This may also have been influenced by the general lack of female Senegalese migrants, who would typically be 


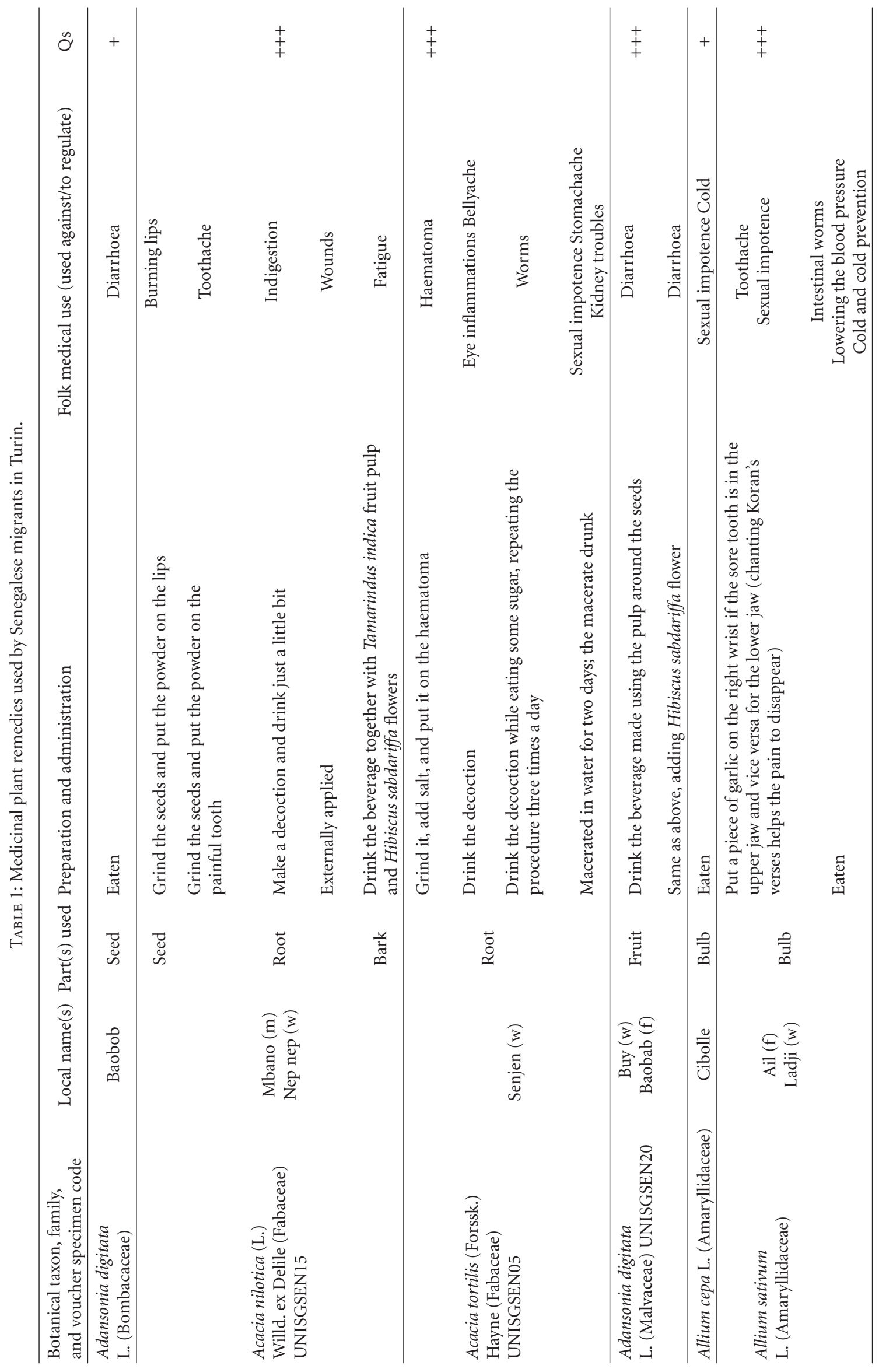




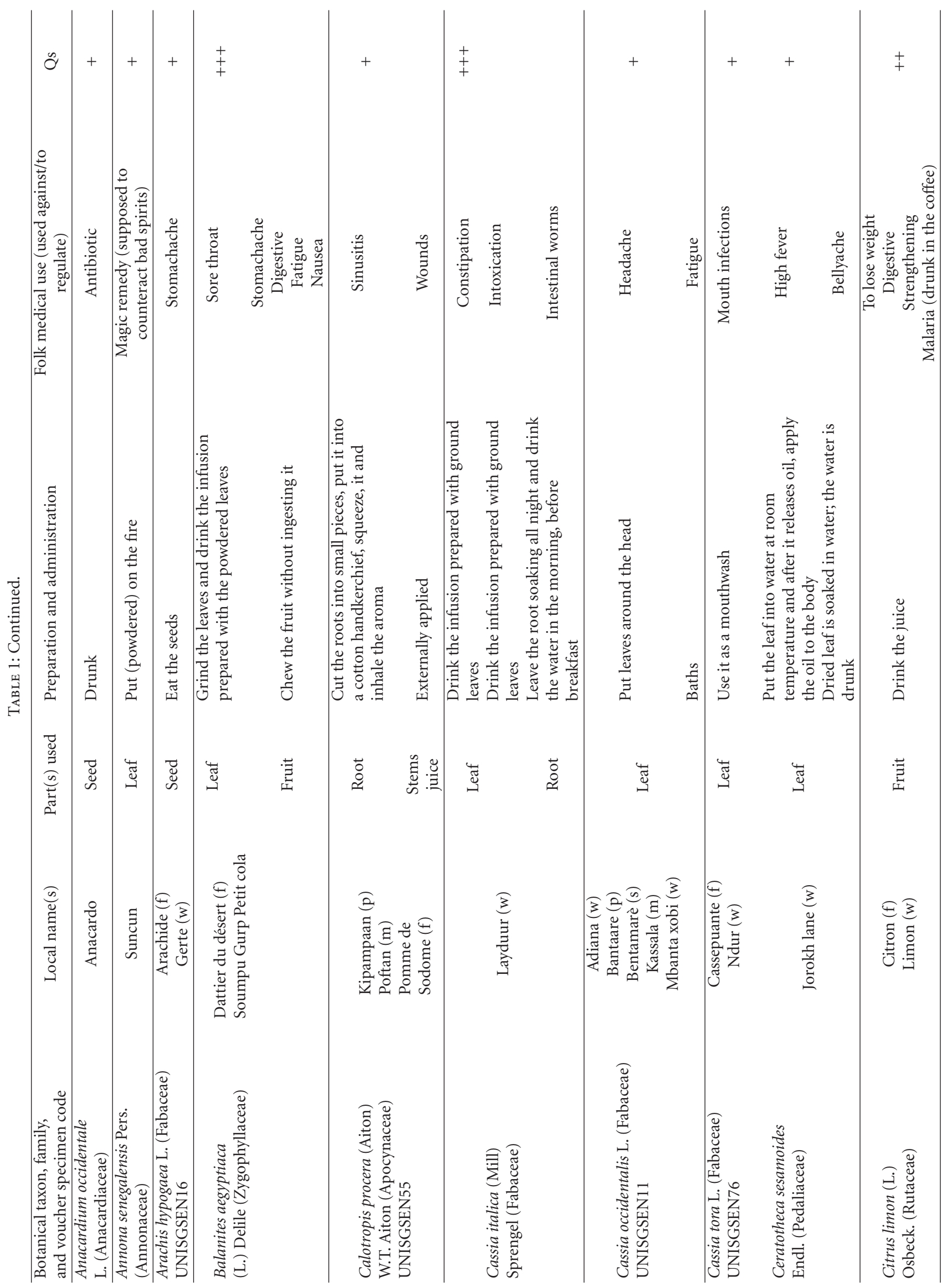




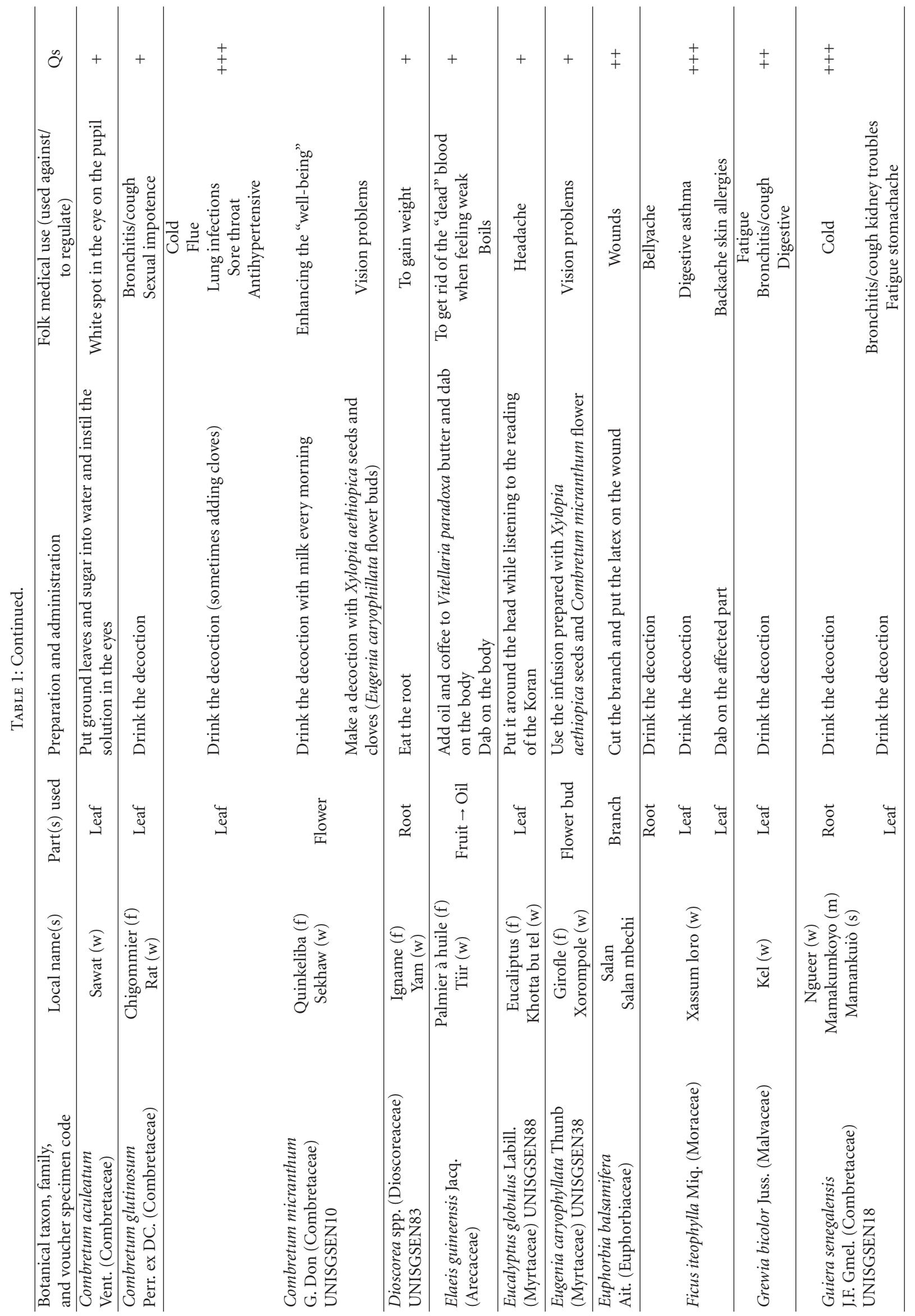




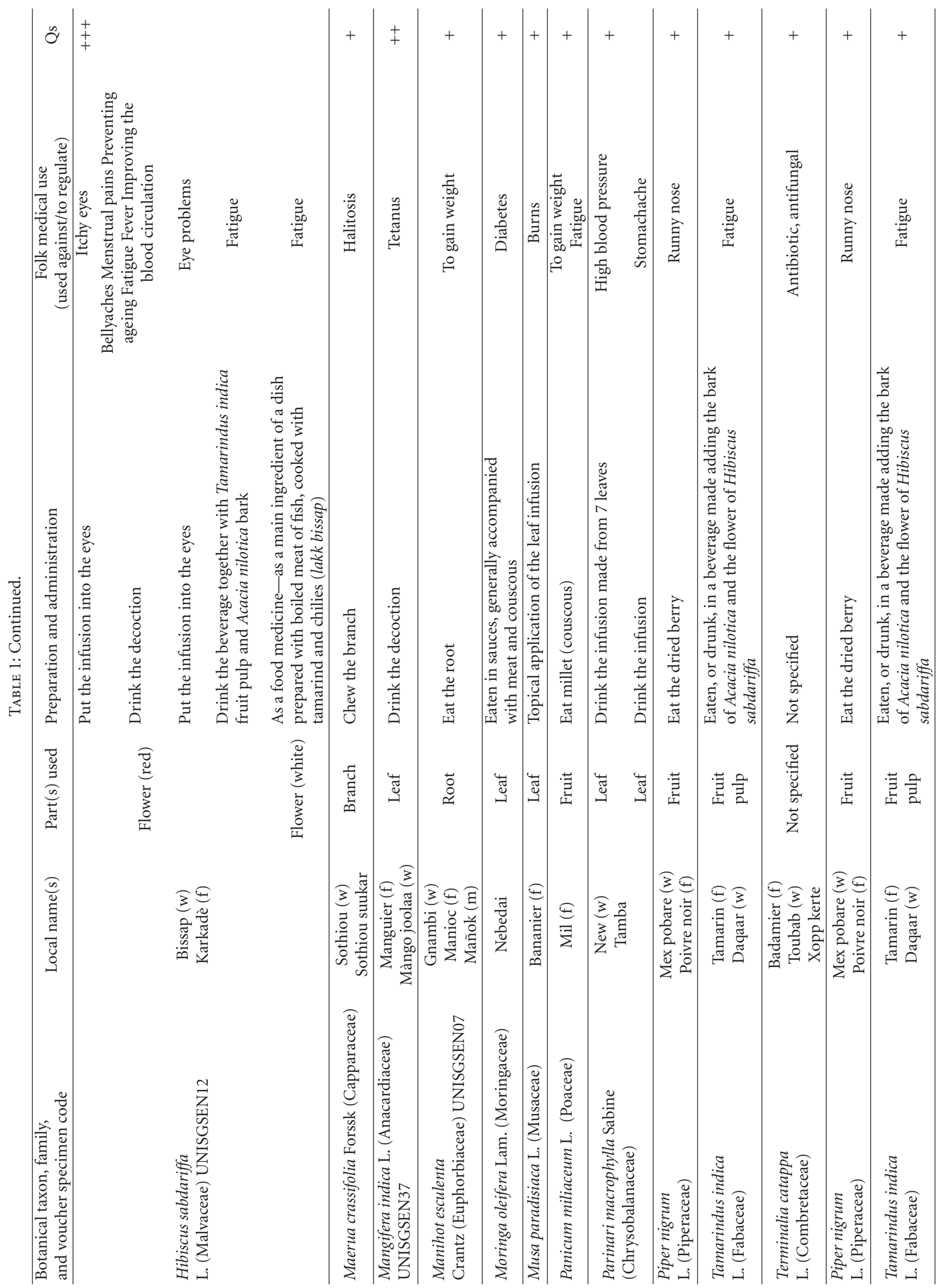




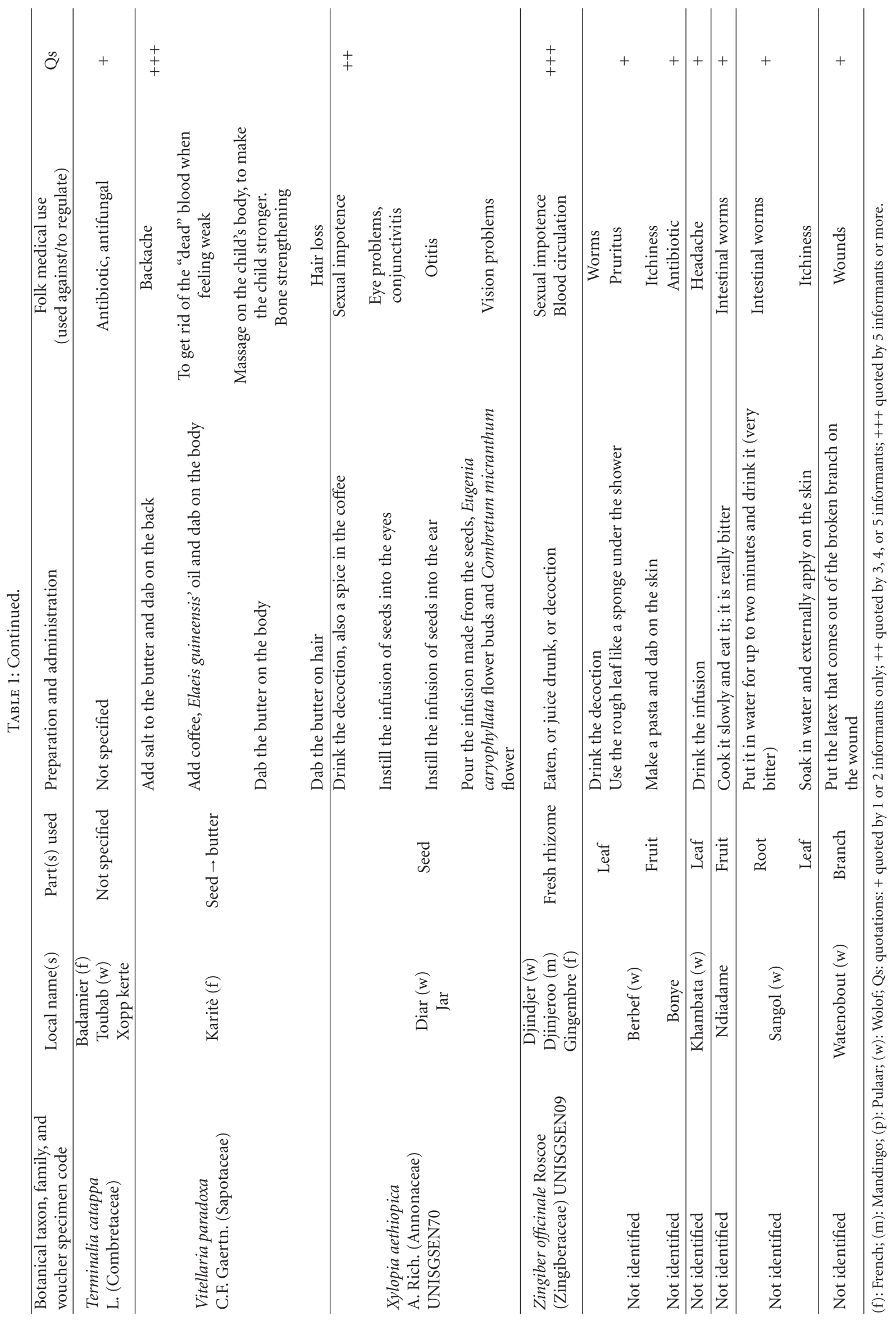




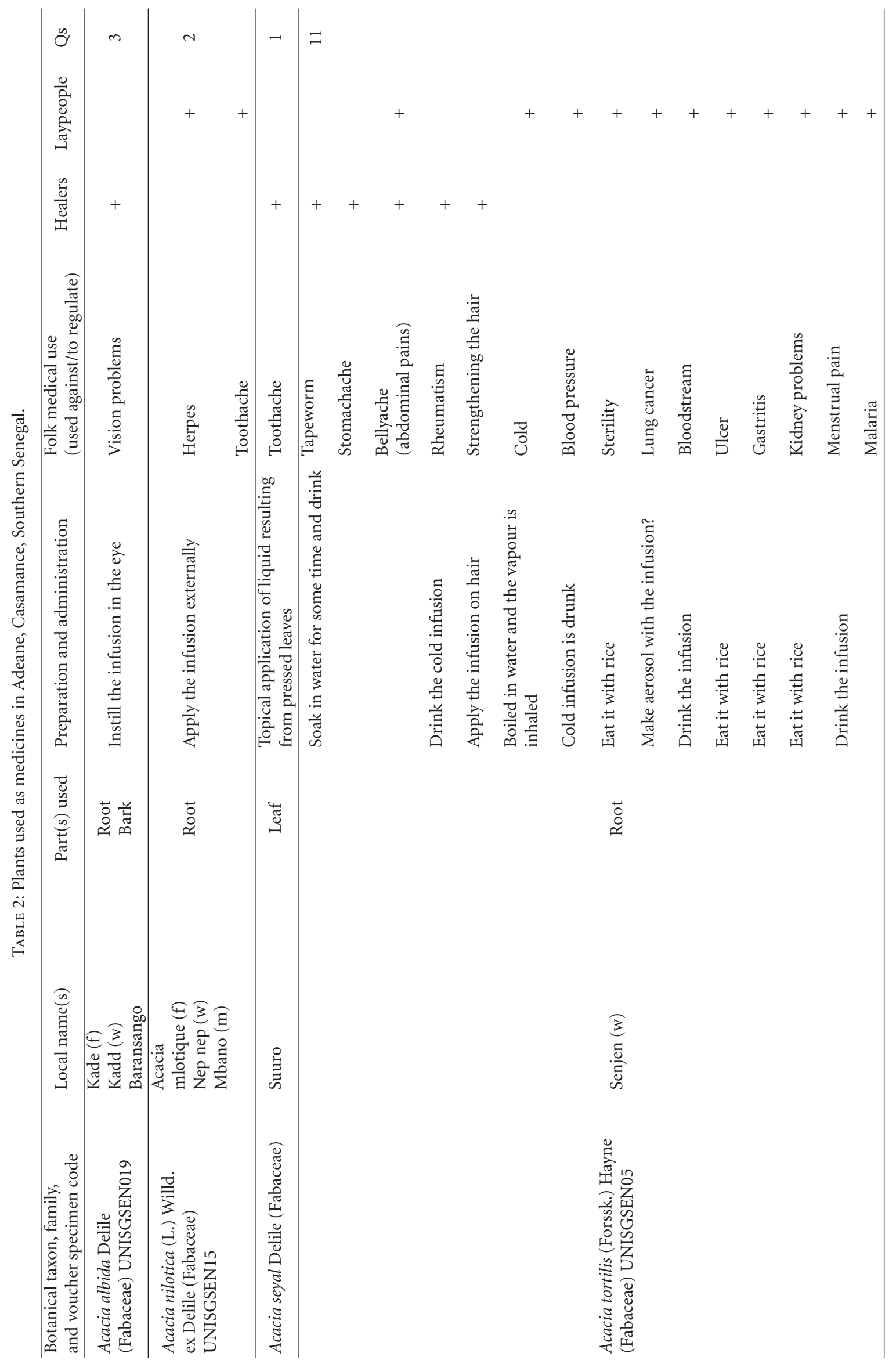




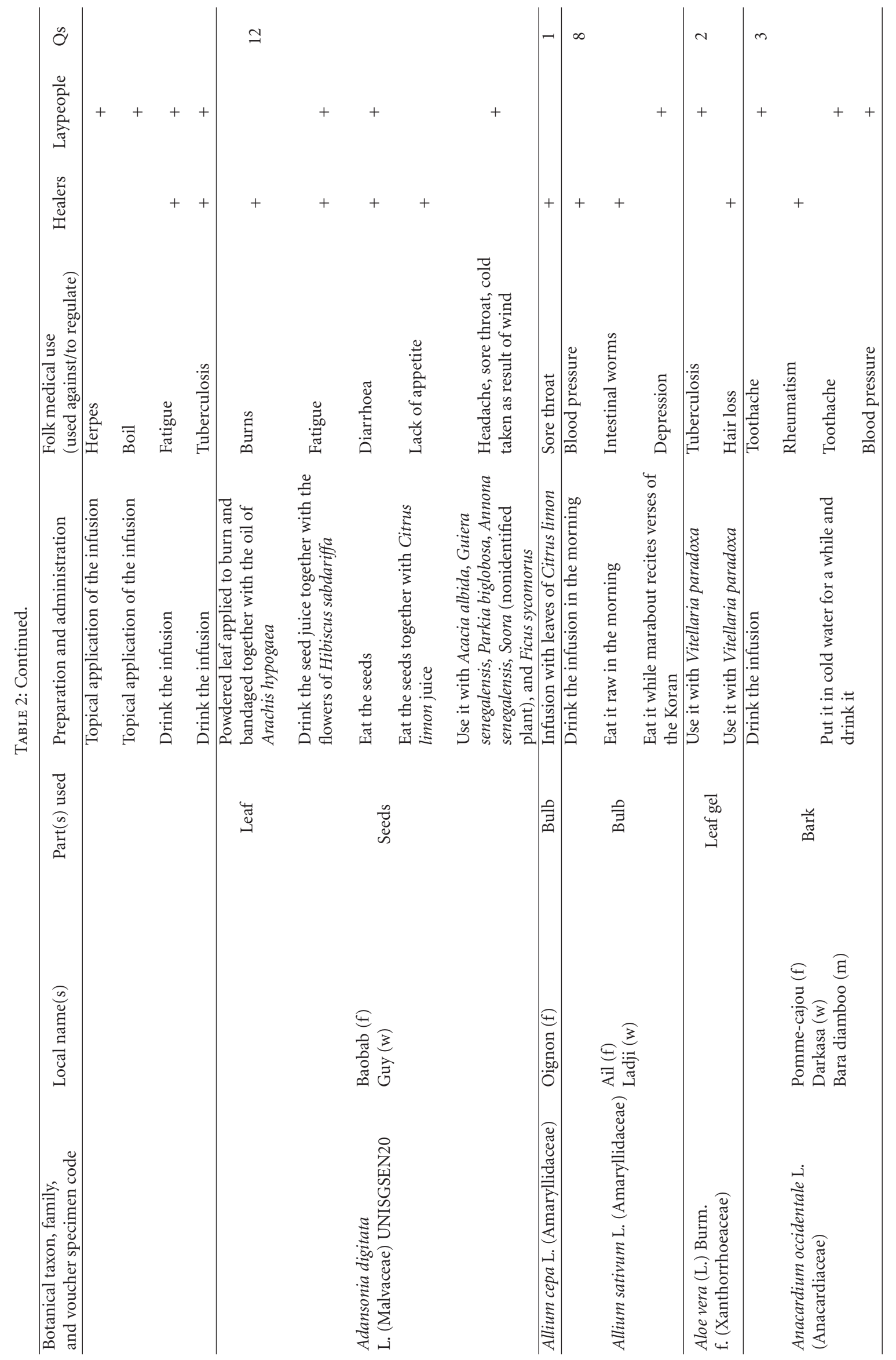




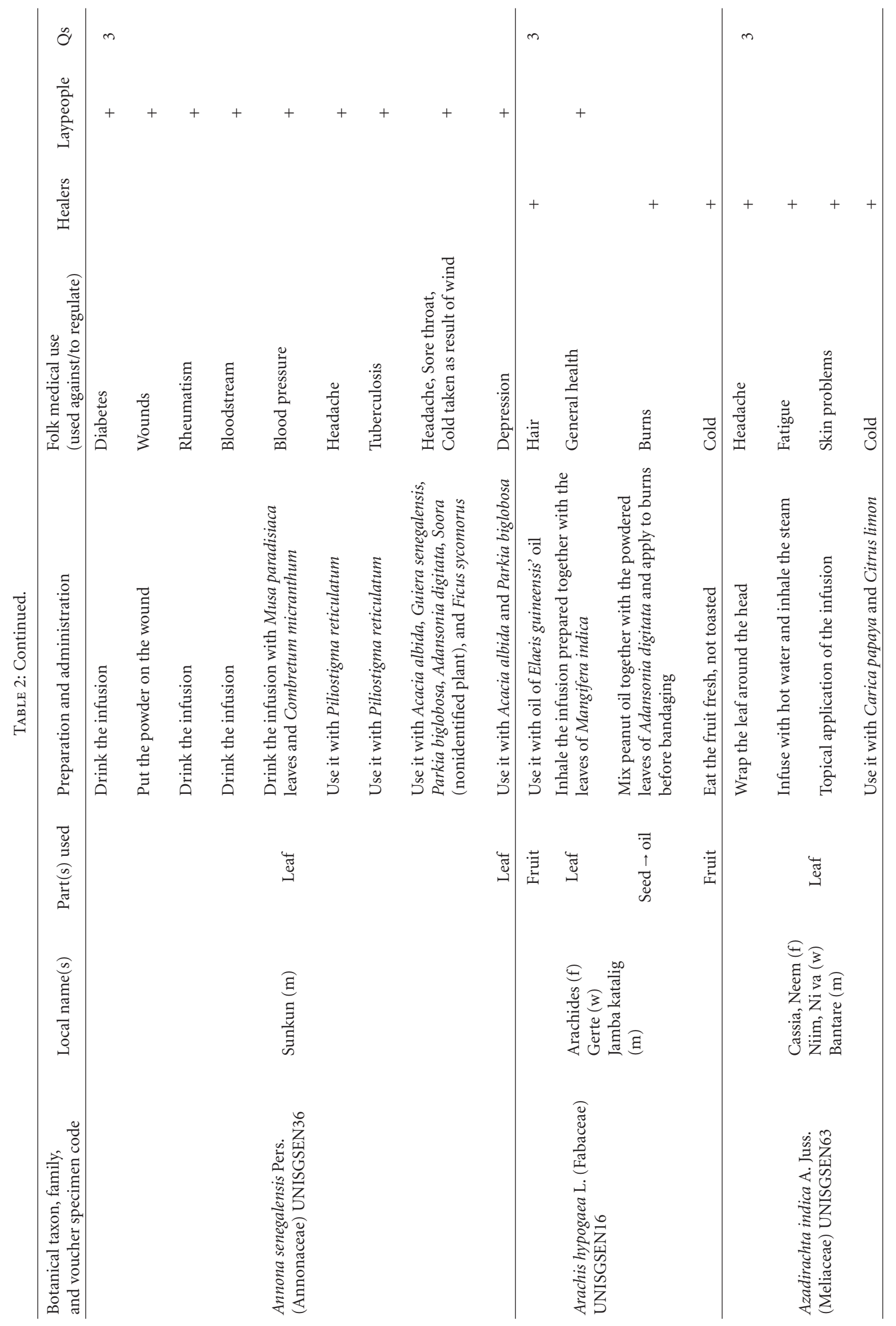




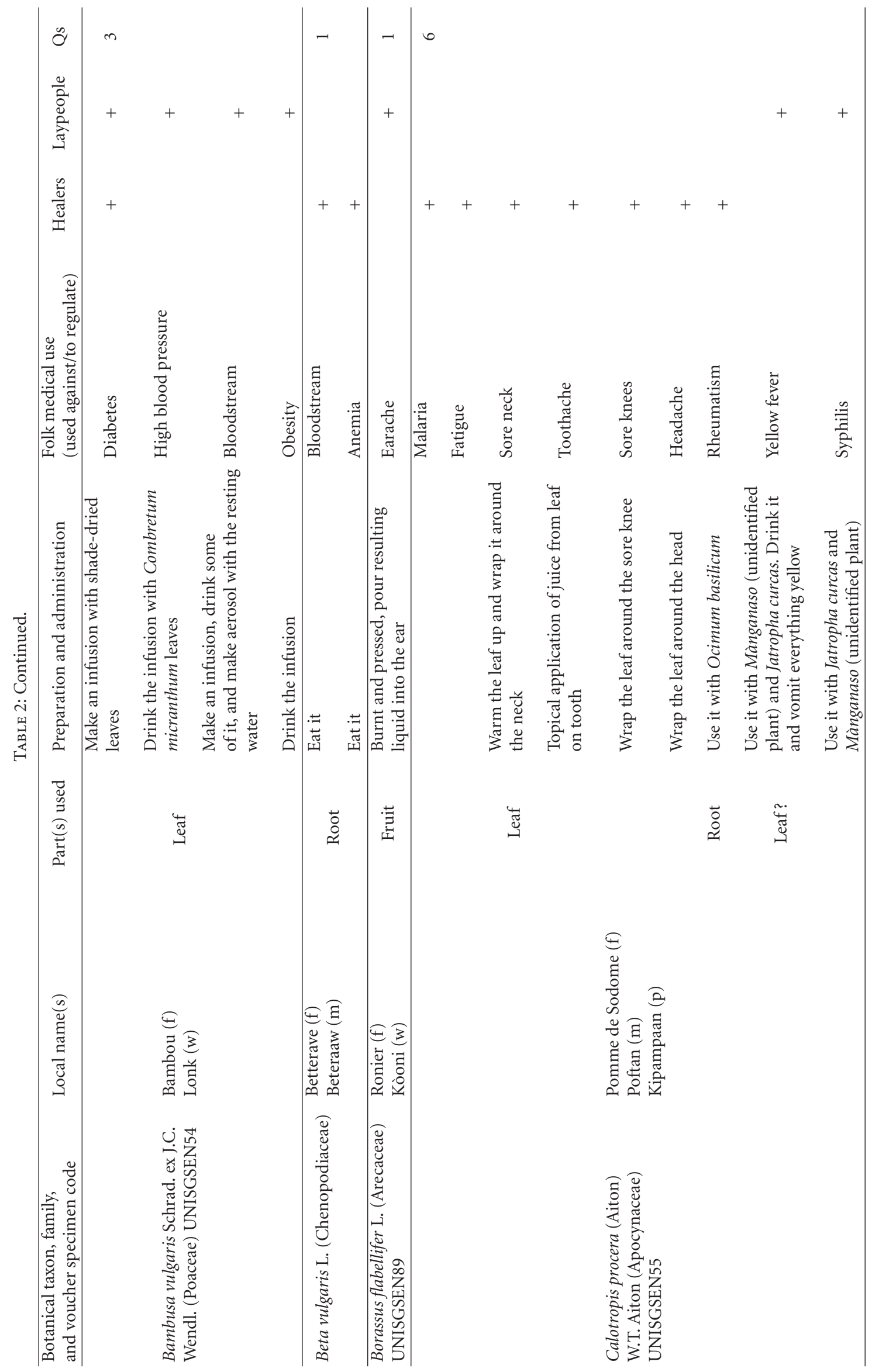




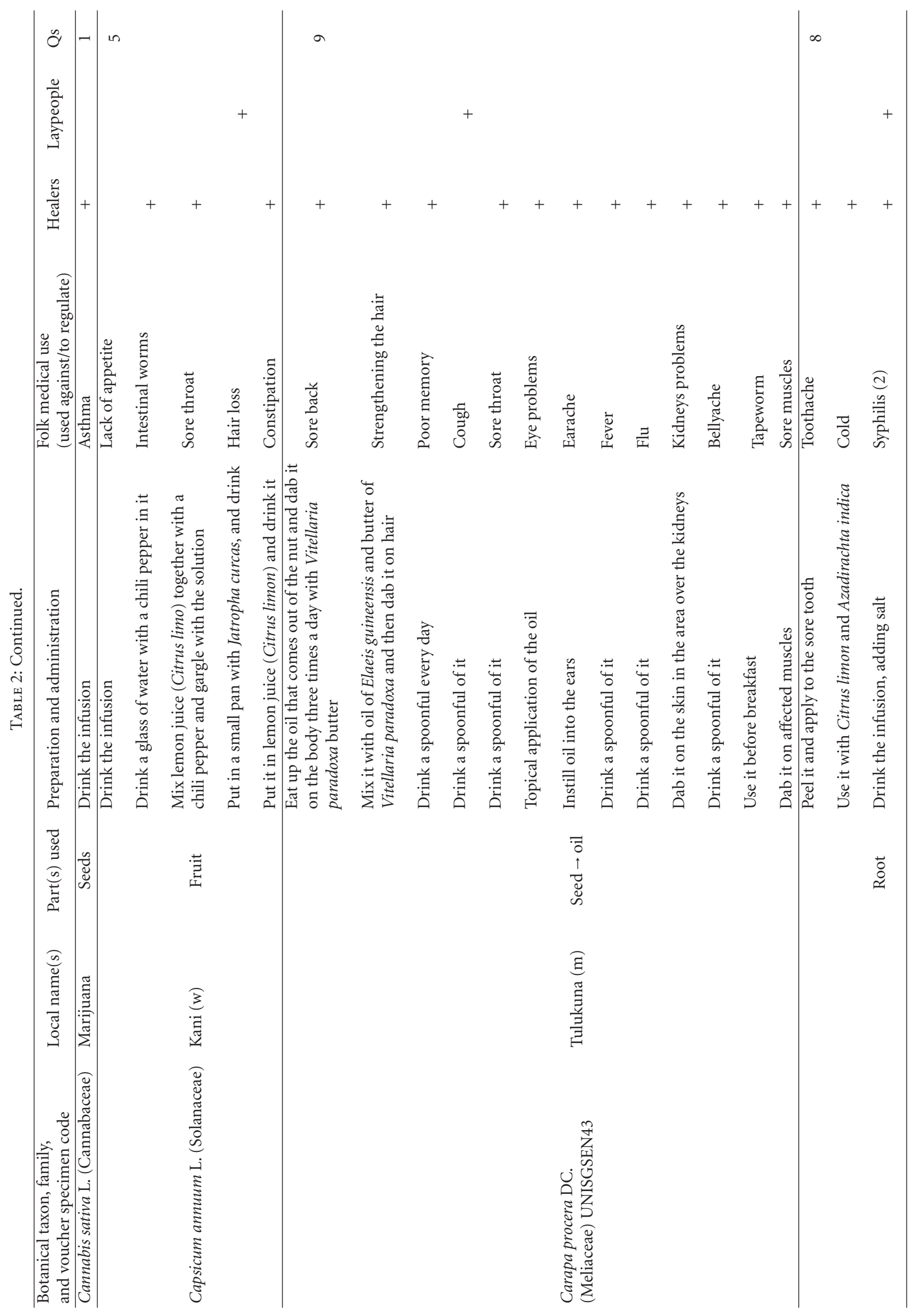




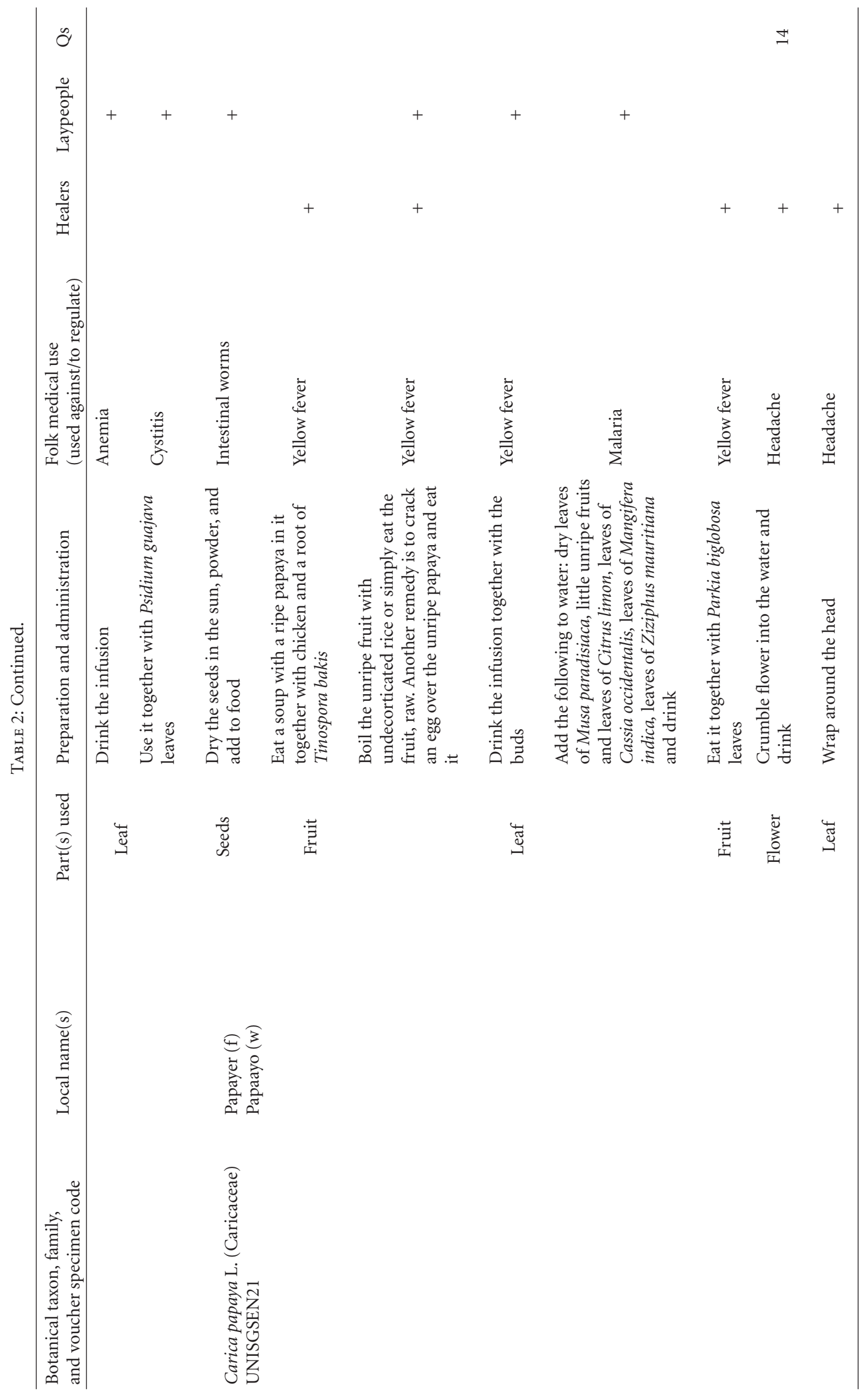




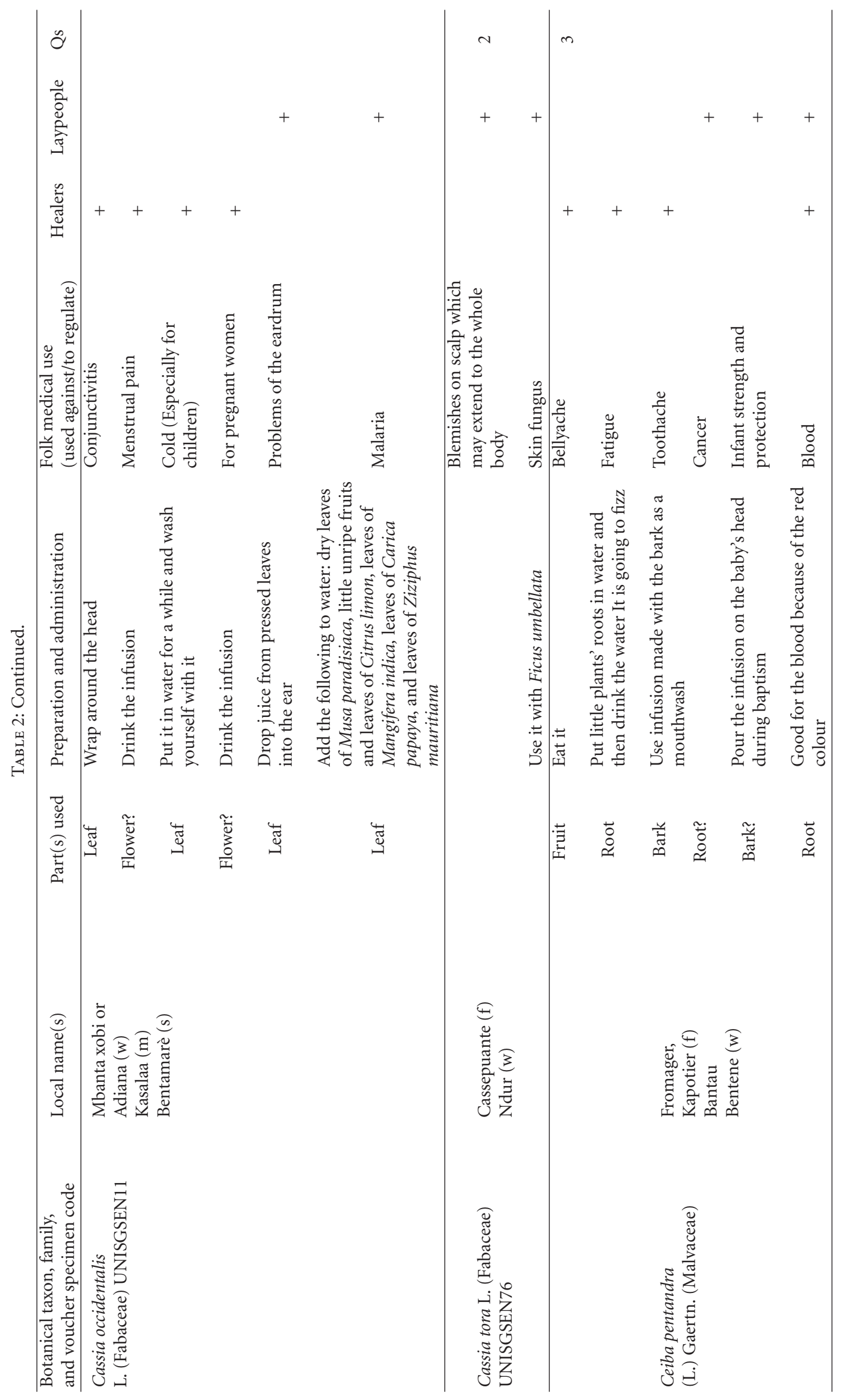




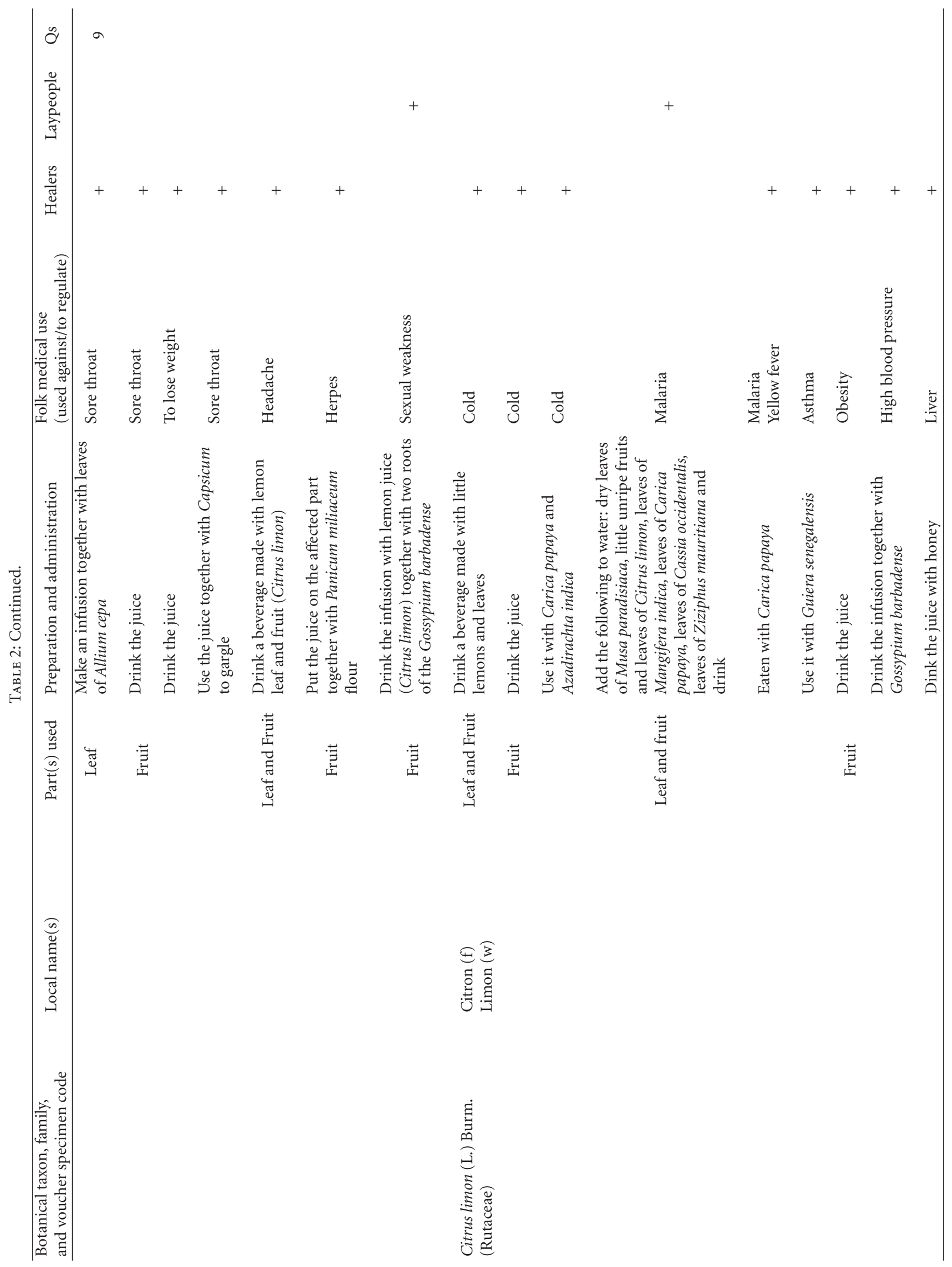




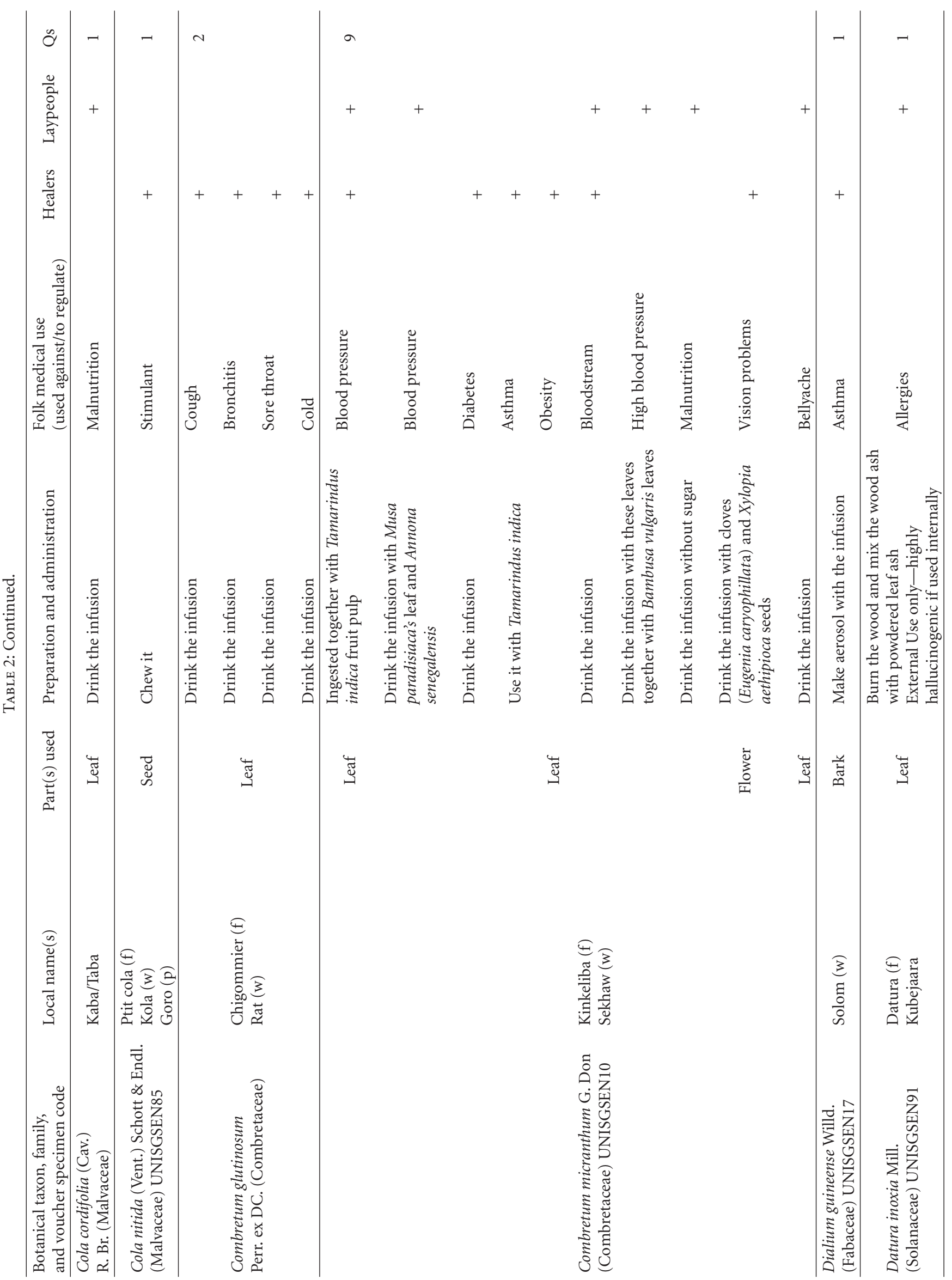




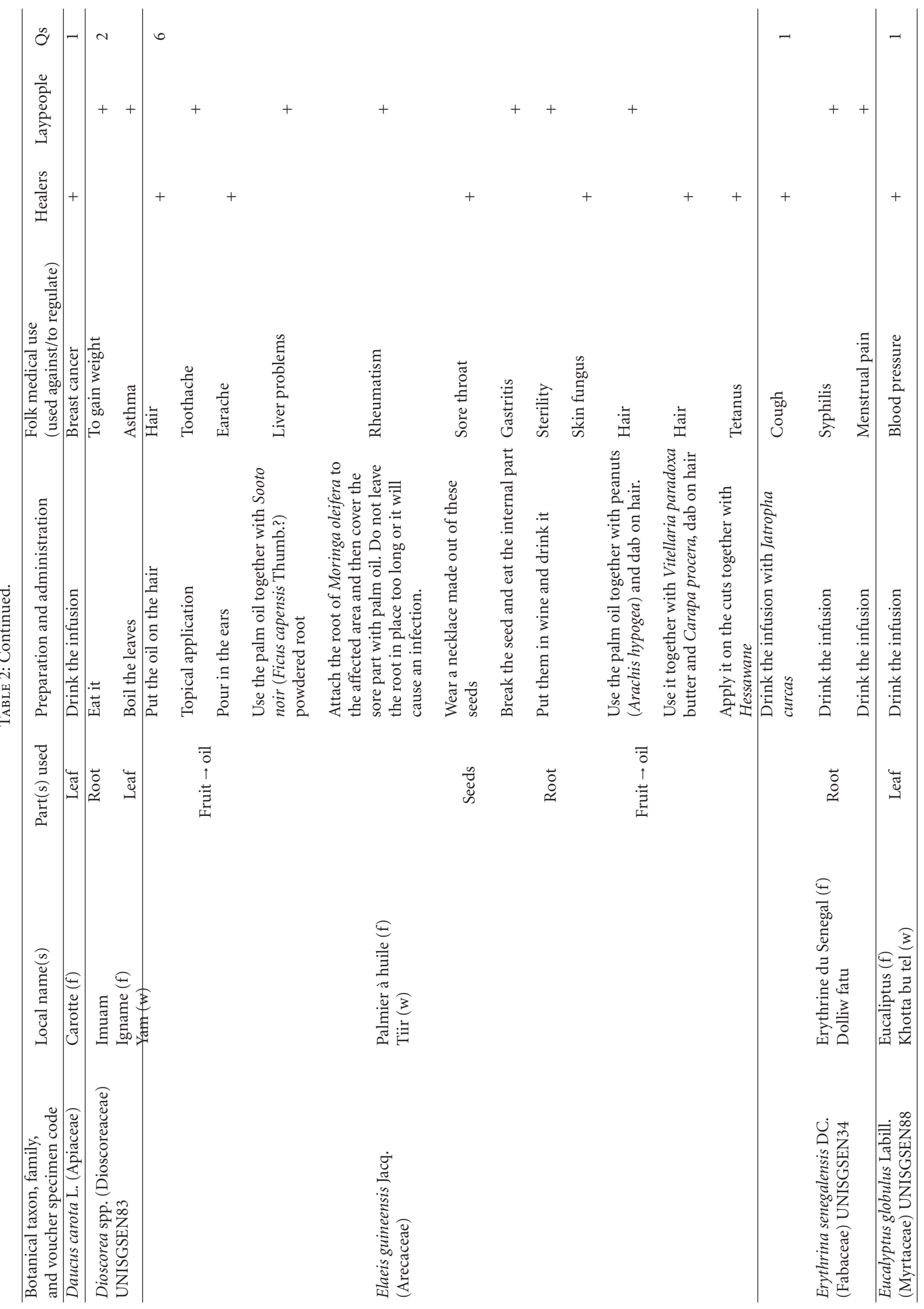




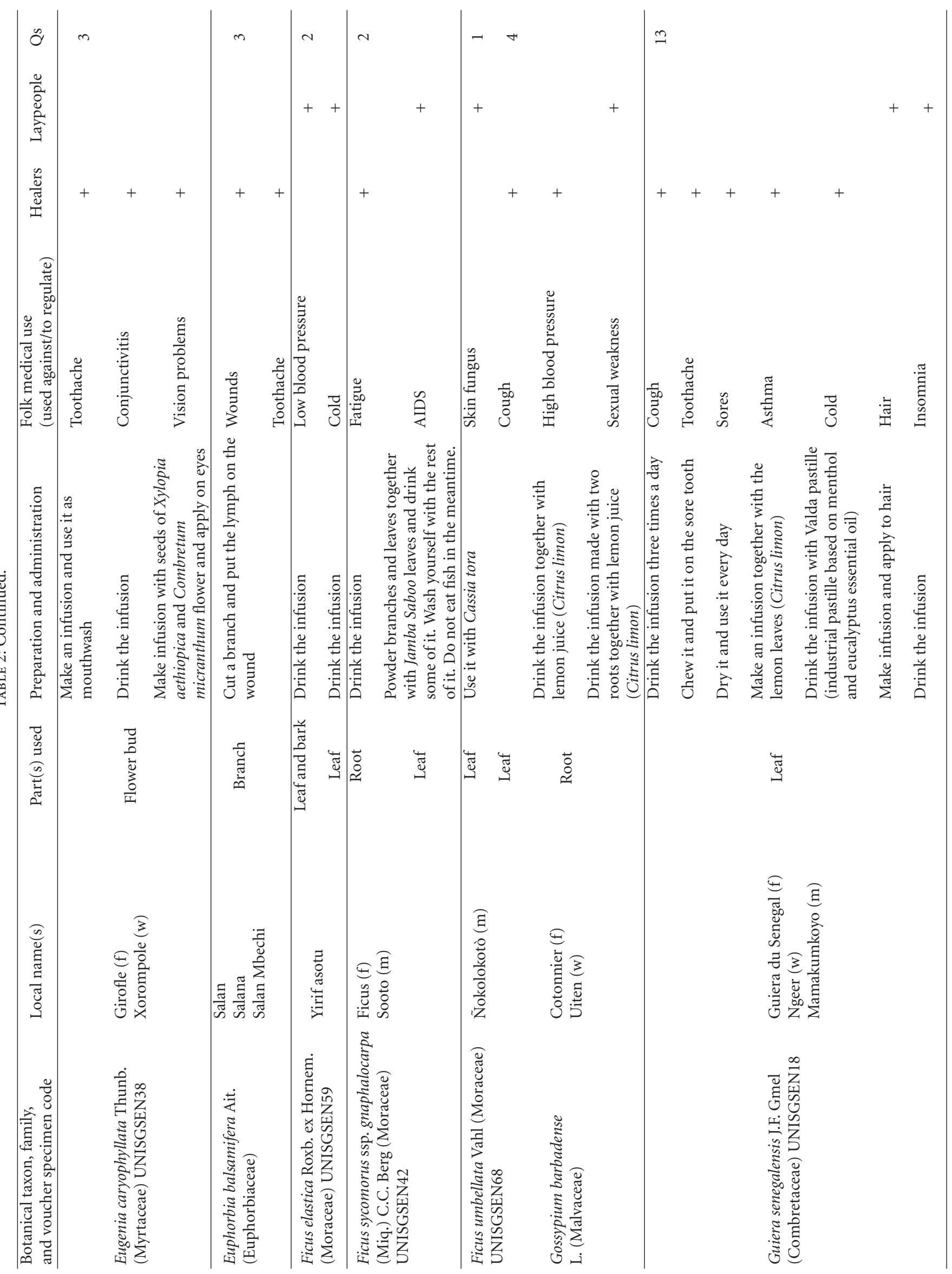




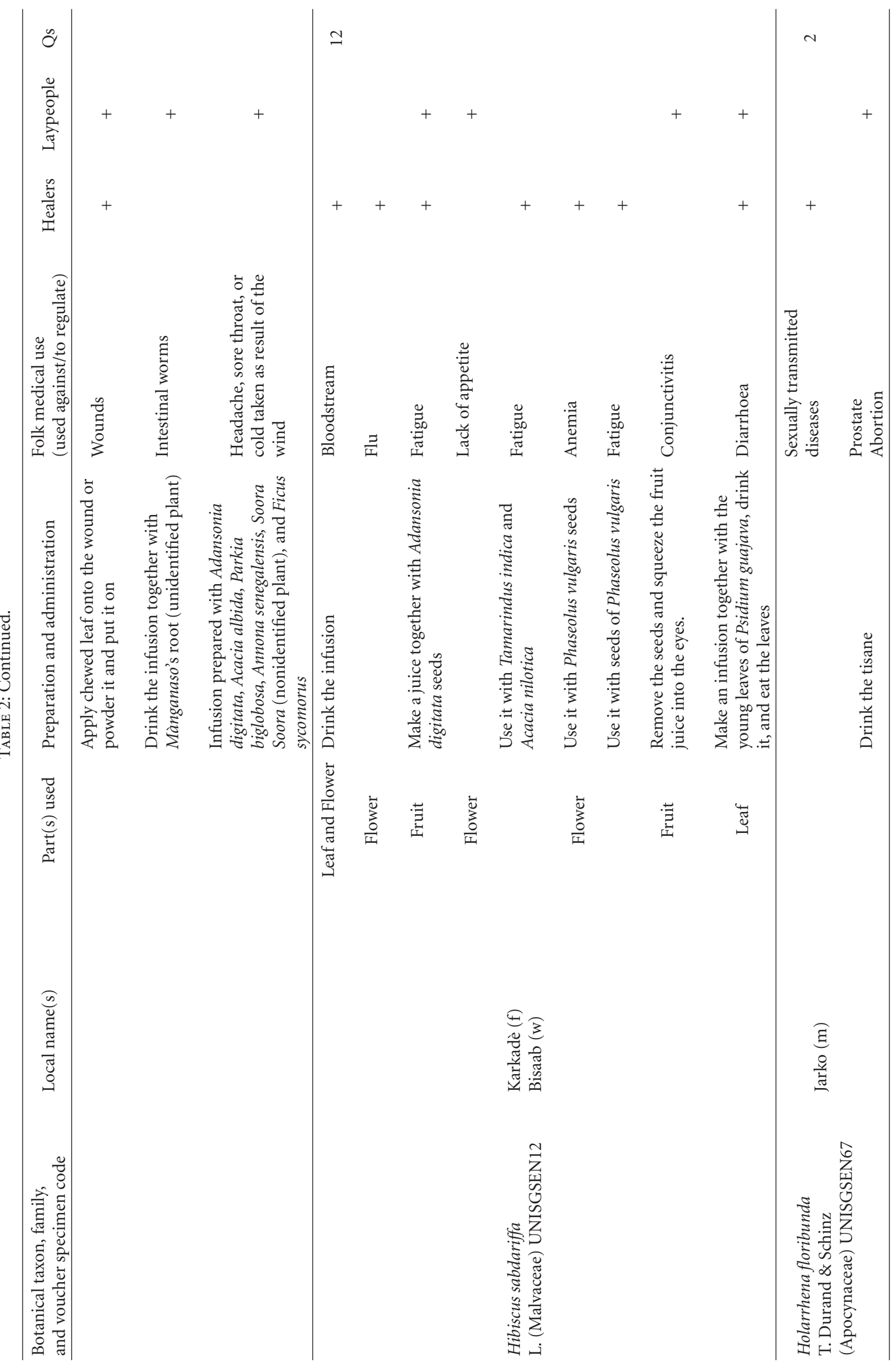




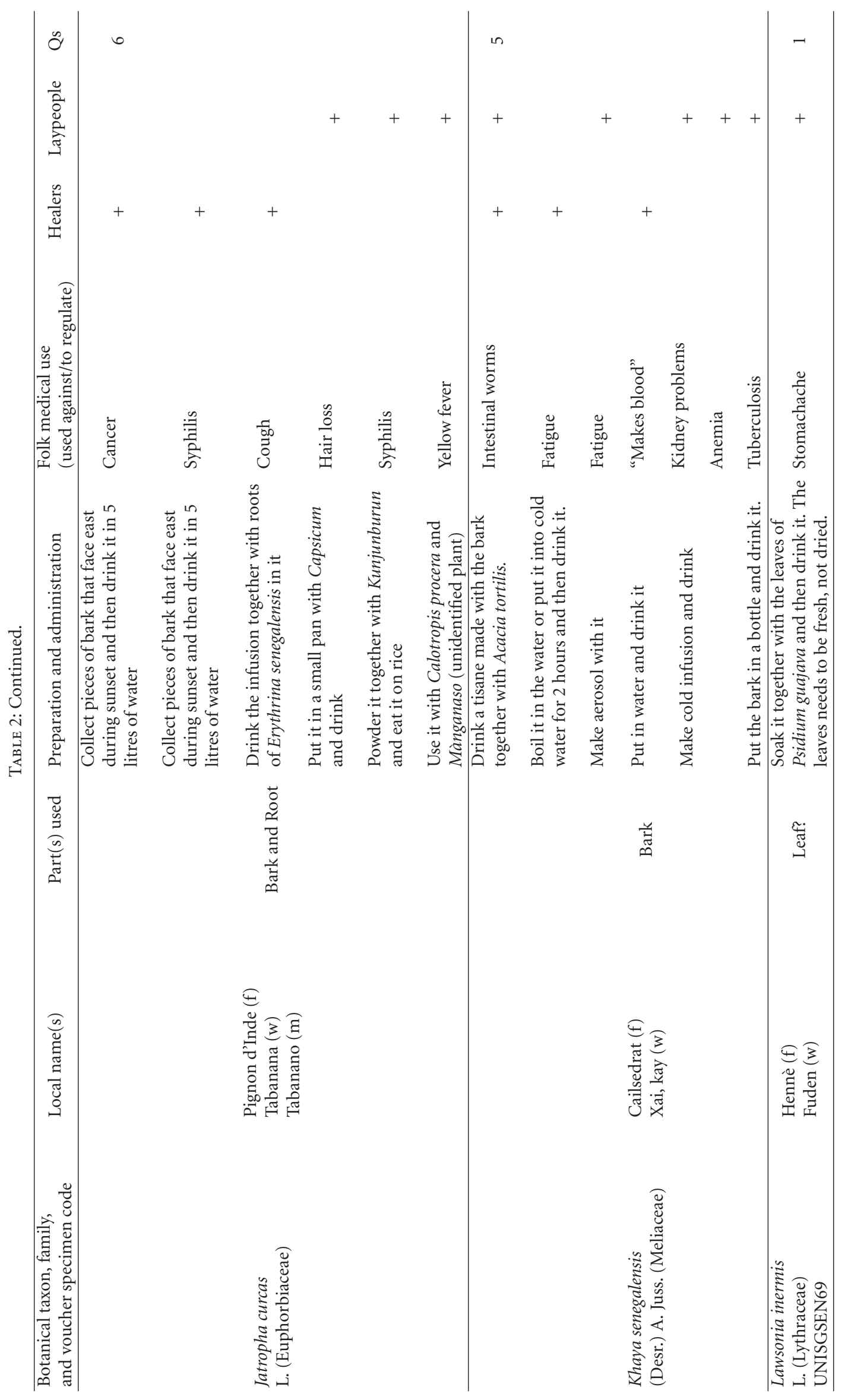




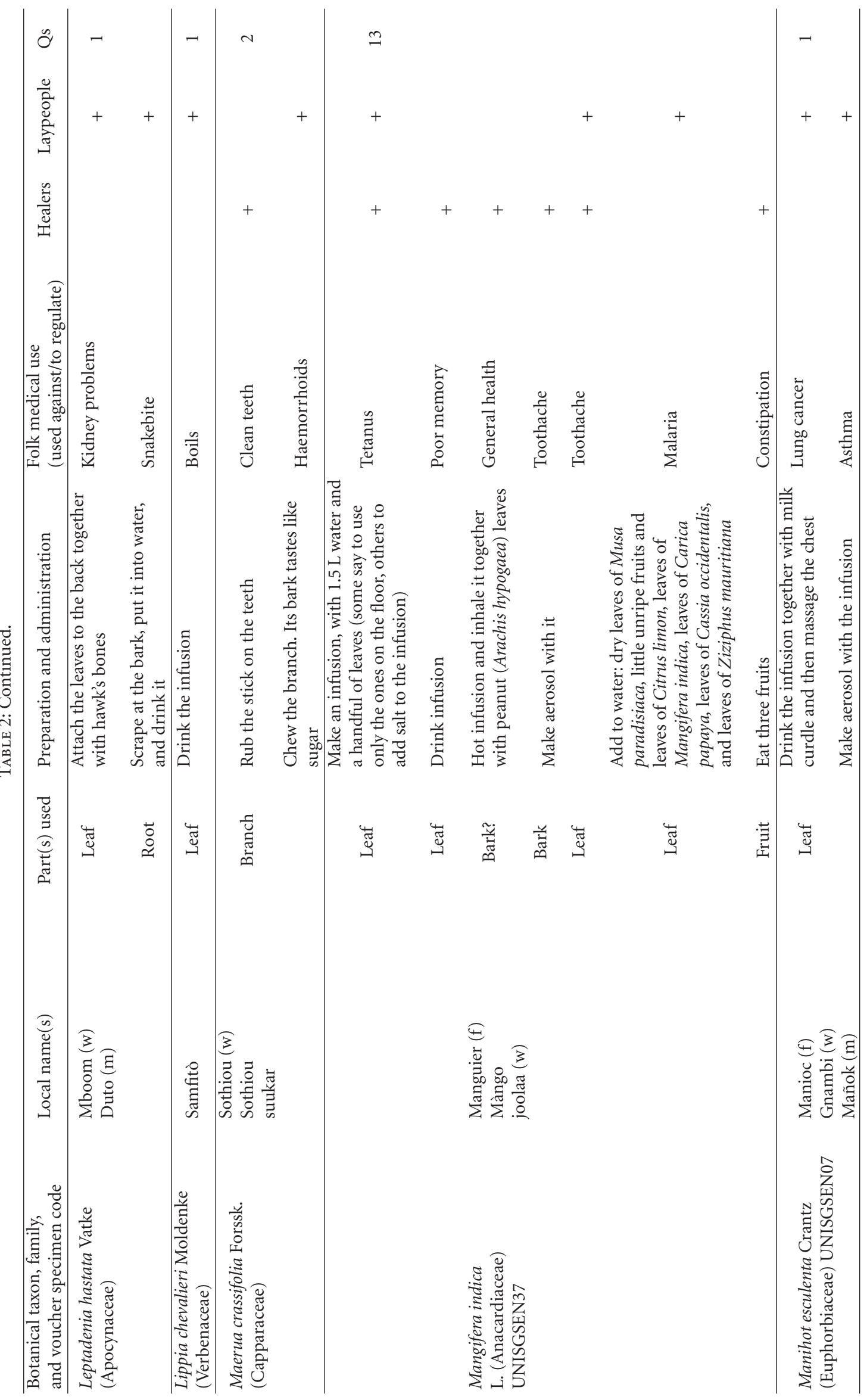




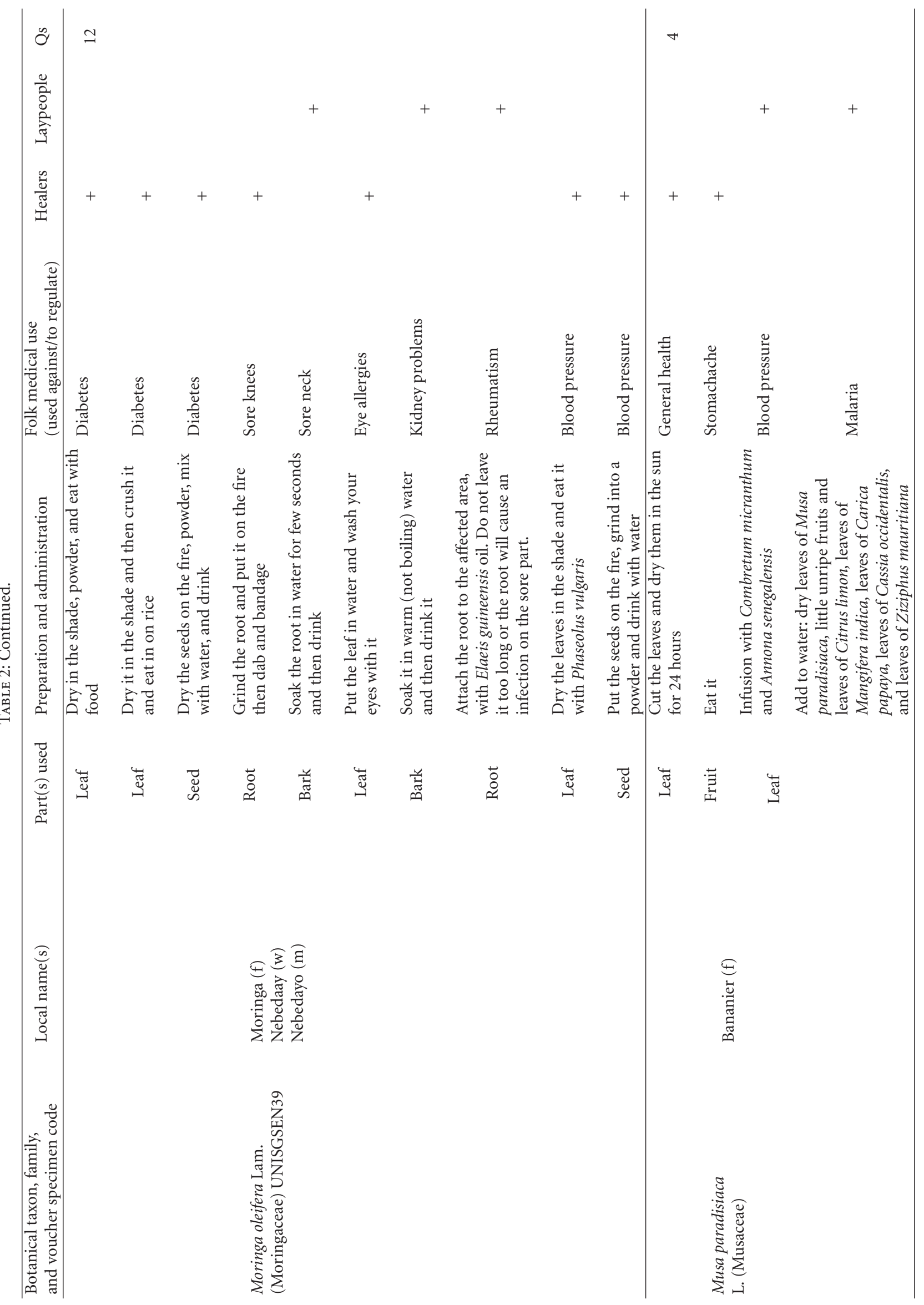




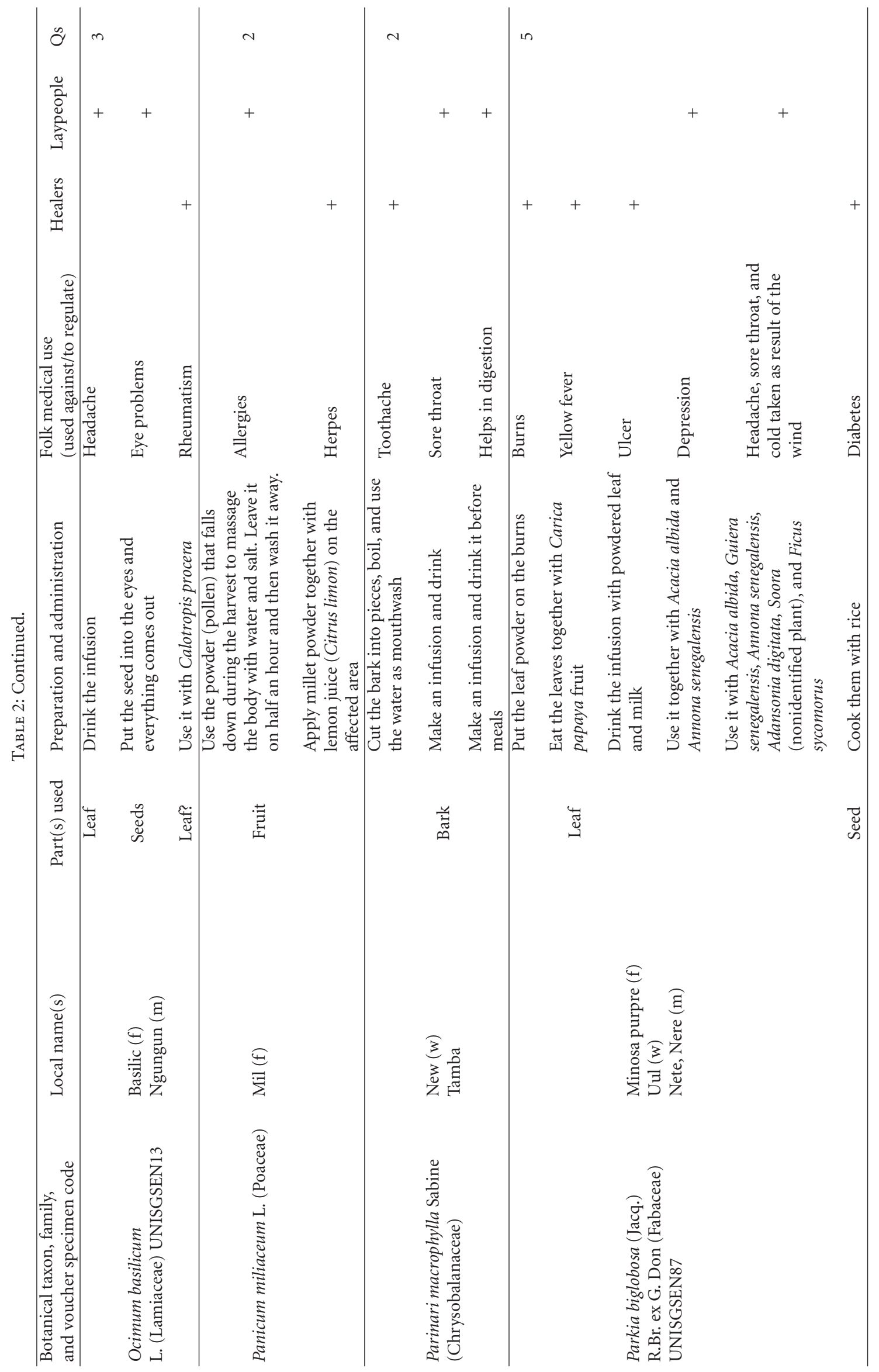




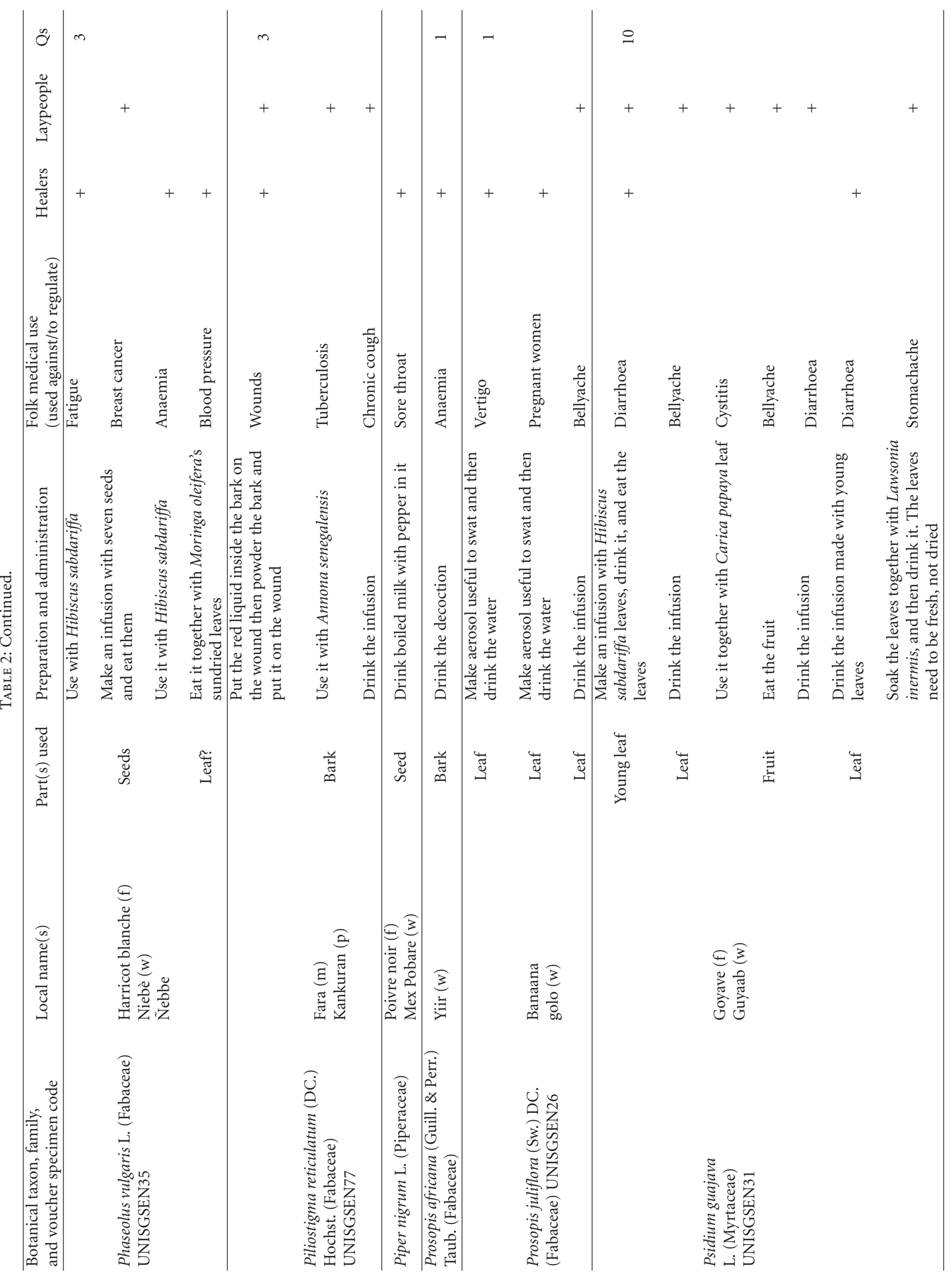




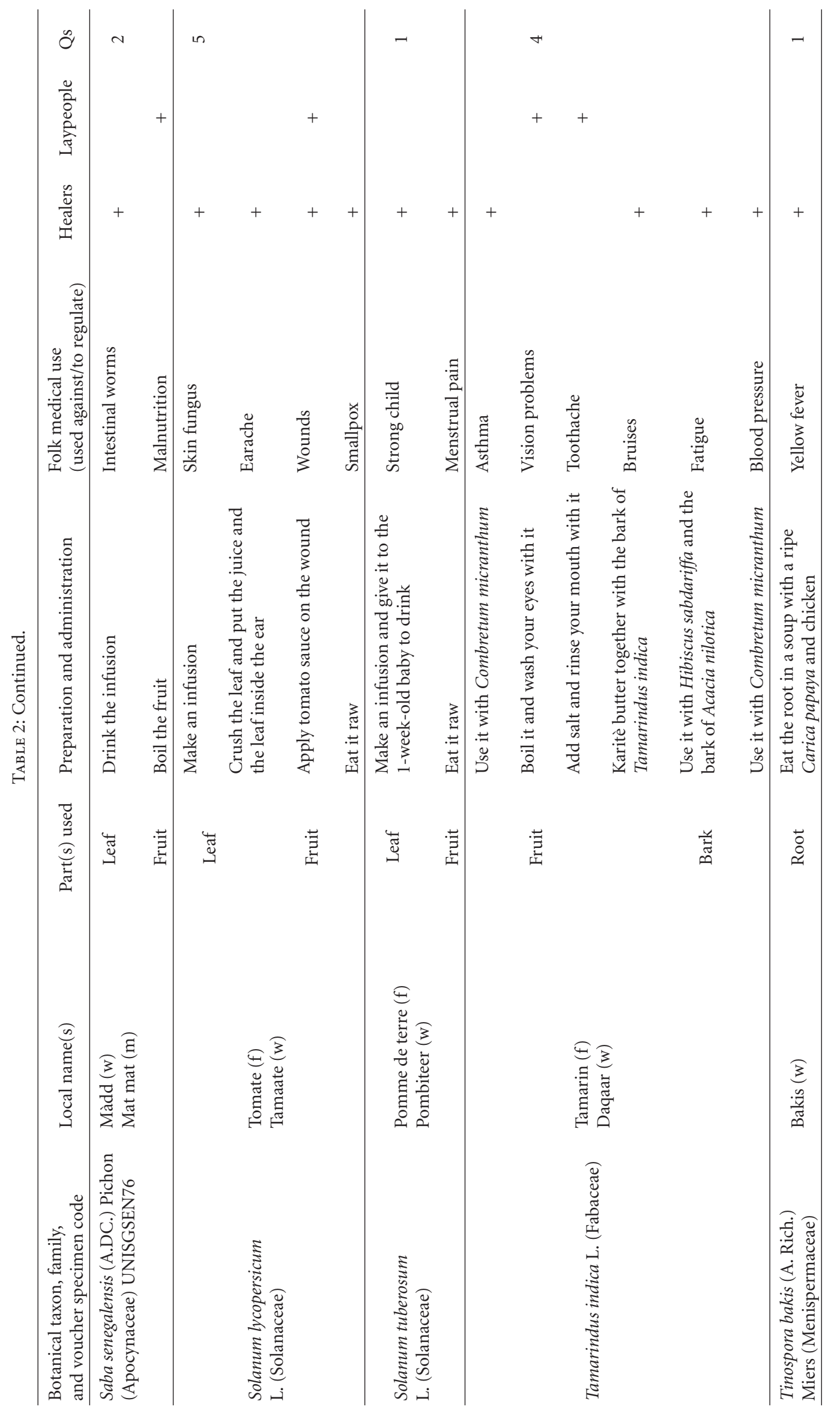




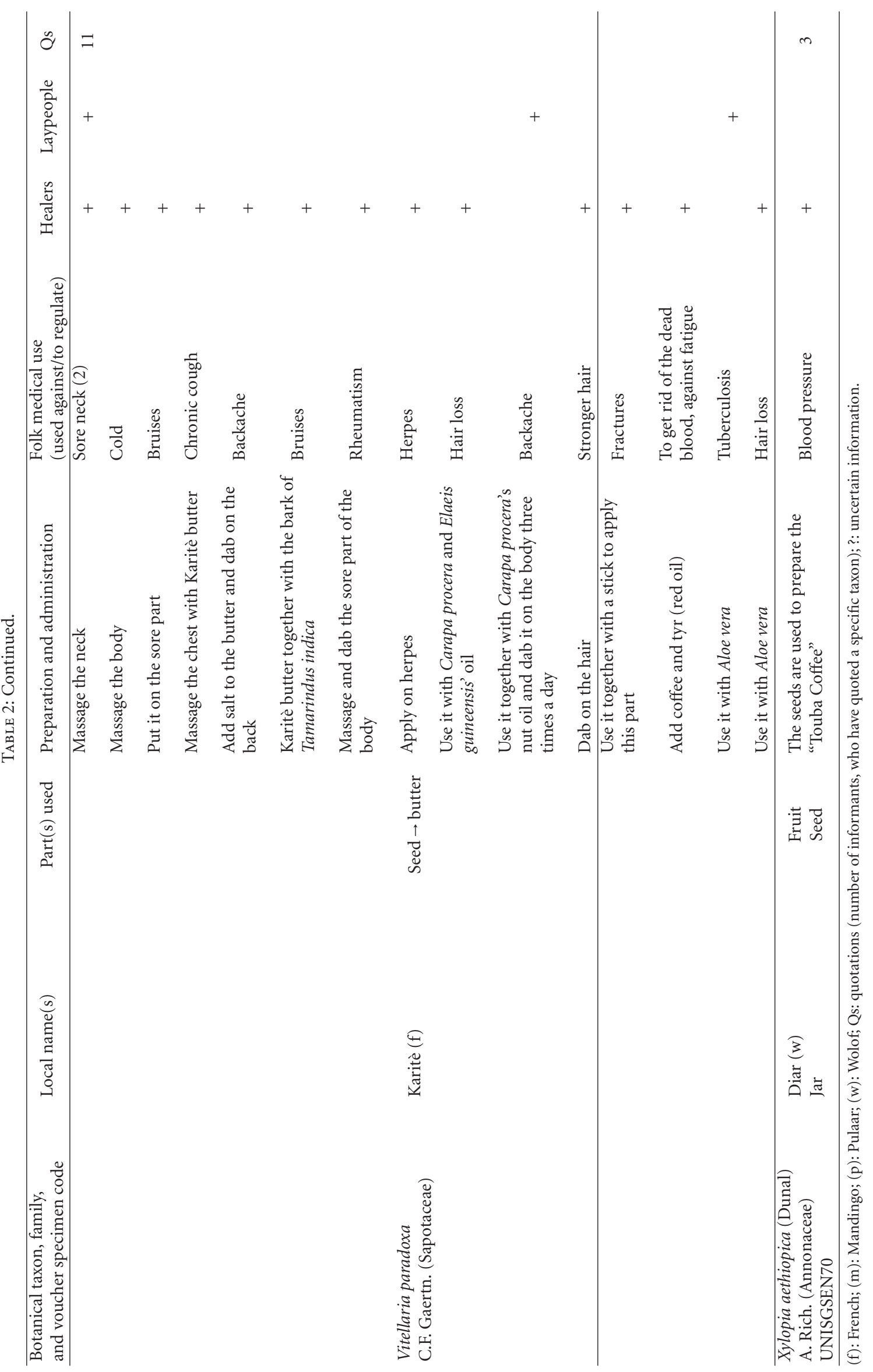


the ones in charge of TM and "health" foods in the domestic setting.

The issues relevant to primary TM practice in migrant communities are often compounded by a lack of specific health policies, which are able to address migrant needs. This problem is, of course, not isolated to the case of migrants in Italy, but is also relevant to many other Western countries, where the healthcare needs of burgeoning migrant populations are often conspicuously absent in health policy and legislation.

By having a better understanding of both the migrant folk pharmacopoeia and the state of TK transmission with regards to health, more culturally sensitive health policies could be developed. In particular, the increasing occurrence of newcomers in Italy should foster more pluralistic approaches in the management of CAMs by the regional authorities, as well as consequently addressing measures aimed to improve the information on potentialities and risks of "home-made" herbal remedies.

\section{Acknowledgments}

Special thanks are due to all of the study participants, who generously agreed to share their knowledge with the first author (R. Ellena). In particular, the authors would like to acknowledge Abdou Faye, Centre d'Education et de Formation Polyvalente, Ziguinchor, Senegal; the NGOs Jamm Italia and Jamm Senegal; the following people: Mamath Ndiaye, Lamine Mane, Adamà Signatte, Kebaman, Majorò Diop, Bu, Amadou Diop, Mamath Ndiaye's grandmother, Awa Diagne, Awa's grandmother, Aicha Ndiaye, Vincent, Modu Modu, Cheik Omar, Khadim, Crip Crap, Mariama, Rama, Fatou, Amadou Diagne, Kabra, Sebia Mendy, Gnana Sahonsla, Ina Signatte, Bin Tagiata, Mohammed Buasi, Solol, Abdullaye, and Abdou Gassama.

\section{References}

[1] M. J. Balick, F. Kronenberg, A. L. Ososki et al., "Medicinal plants used by Latino healers for women's health conditions in New York City," Economic Botany, vol. 54, no. 3, pp. 344-357, 2000.

[2] I. Vandebroek, M. J. Balick, A. Ososki et al., "The importance of botellas and other plant mixtures in Dominican traditional medicine," Journal of Ethnopharmacology, vol. 128, no. 1, pp. 20-41, 2010.

[3] M. J. Balick and R. Lee, "Looking within: urban ethnomedicine and ethnobotany," Alternative Therapies in Health and Medicine, vol. 7, no. 4, pp. 114-115, 2001.

[4] A. Waldstein, "Mexican migrant ethnopharmacology: pharmacopoeia, classification of medicines and explanations of efficacy," Journal of Ethnopharmacology, vol. 108, no. 2, pp. 299-310, 2006.

[5] A. Pieroni and I. Vandebroek, Traveling Cultures and Plants: The Ethnobiology and Ethnopharmacy of Human Migrations, Berghahn, New York, NY, USA, 2007.

[6] A. Pieroni and C. Gray, "Herbal and food folk medicines of the Russlanddeutschen living in Künzelsau/Taläcker, SouthWestern Germany," Phytotherapy Research, vol. 22, no. 7, pp. 889-901, 2008.
[7] A. Pieroni, H. Muenz, M. Akbulut, K. H. C. Başer, and C. Durmuşkahya, "Traditional phytotherapy and trans-cultural pharmacy among Turkish migrants living in Cologne, Germany," Journal of Ethnopharmacology, vol. 102, no. 1, pp. 6988, 2005.

[8] P. C. Lundberg, "Use of traditional herbal remedies by Thai immigrant women in Sweden," in Travelling Cultures, Plants and Medicines The Ethnobiology and Ethnopharmacy of Human Migrations, A. Pieroni and I. Vandebroek, Eds., pp. 104-121, Berghahn, New York, NY, USA, 2007.

[9] T. van Andel and P. Westers, "Why Surinamese migrants in the Netherlands continue to use medicinal herbs from their home country," Journal of Ethnopharmacology, vol. 127, no. 3, pp. 694-701, 2010.

[10] T. van Andel and C. van't Klooster, "Medicinal plant use by Surinamese immigrants in Amsterdam, the Netherlands: results of a pilot market survey," in Travelling Cultures, Plants and Medicines The Ethnobiology and Ethnopharmacy of Human Migrations, A. Pieroni and I. Vandebroek, Eds., pp. 122-144, Berghahn, New York, NY, USA, 2007.

[11] A. Pieroni, H. Zaman, S. Ayub, and B. Torry, "My doctor doesn't understand why I use them," in Herbal and Food Medicines Amongst the Bangladeshi Community in West Yorkshire, UK, M. Pardo de Santayana, A. Pieroni, and R. Puri, Eds., pp. 112-146, Ethnobotany in the New Europe People, Health and Wild Plant Resources, Berghahn, Oxford, UK, 2010.

[12] D. S. Sandhu and M. Heinrich, "The use of health foods, spices and other botanicals in the sikh community in London," Phytotherapy Research, vol. 19, no. 7, pp. 633-642, 2005.

[13] A. Pieroni, L. Houlihan, N. Ansari, B. Hussain, and S. Aslam, "Medicinal perceptions of vegetables traditionally consumed by South-Asian migrants living in Bradford, Northern England," Journal of Ethnopharmacology, vol. 113, no. 1, pp. 100110, 2007.

[14] A. Pieroni, Q. Z. Sheikh, W. Ali, and B. Torry, "Traditional medicines used by Pakistani migrants from Mirpur living in Bradford, Northern England," Complementary Therapies in Medicine, vol. 16, no. 2, pp. 81-86, 2008.

[15] M. Ceuterick, I. Vandebroek, B. Torry, and A. Pieroni, "The use of home-remedies for health care and well-being by Spanish Latino immigrants in London: a reflection on acculturation," in Travelling Plants and Cultures The Ethnobiology and Ethnopharmacy of Human Migrations, A. Pieroni and I. Vandebroek, Eds., Berghahn, New York, NY, USA, 2007.

[16] M. Ceuterick, I. Vandebroek, B. Torry, and A. Pieroni, "Crosscultural adaptation in urban ethnobotany: the Colombian folk pharmacopoeia in London," Journal of Ethnopharmacology, vol. 120, no. 3, pp. 342-359, 2008.

[17] M. Ceuterick, I. Vandebroek, and A. Pieroni, "Resilience of Andean urban ethnobotanies: a comparison of medicinal plant use among Bolivian and Peruvian migrants in the United Kingdom and in their countries of origin," Journal of Ethnopharmacology, vol. 136, no. 1, pp. 27-54, 2011.

[18] Caritas/Migrantes, "Immigrazione. Dossier Statistico. $\mathrm{XX}^{\circ}$ Rapporto,” Rom: Idos, 2010.

[19] B. Riccio, "West African transnationalisms compared: ghanaians and senegalese in Italy," Journal of Ethnic and Migration Studies, vol. 34, no. 2, pp. 217-234, 2008.

[20] G. Sinatti, “"Mobile transmigrants” or "unsettled returnees”? myth of return and permanent resettlement among Senegalese migrants," Population, Space and Place, vol. 17, no. 2, pp. 153166, 2011. 
[21] G. Sinatti, "Home is where the heart abides migration, return and housing in Dakar, Senegal," Open House International, vol. 34, no. 3, pp. 49-56, 2009.

[22] M. G. Carta, P. Coppo, M. A. Reda, M. C. Hardoy, and B. Carpiniello, "Depression and social change. From transcultural psychiatry to a constructivist model," Epidemiologia $e$ Psichiatria Sociale, vol. 10, no. 1, pp. 46-58, 2001.

[23] J. Andall, "Immigration and the Italian left democrats in government (1996-2001)," Patterns of Prejudice, vol. 41, no. 2, pp. 131-153, 2007.

[24] N. Mai, "The Albanian diaspora-in-the-making: media, migration and social exclusion," Journal of Ethnic and Migration Studies, vol. 31, no. 3, pp. 543-561, 2005.

[25] N. Mai, "The politicisation of migrant minors: italo-Romanian geopolitics and EU integration," Area, vol. 42, no. 2, pp. 181-189, 2010.

[26] N. Sigona, “"Gypsies out of Italy!”: social exclusion and racial discrimination of Roma and Sinti in Italy," in Italy Today The Sick Man of Europe, A. Mammone and G. A. Veltri, Eds., pp. 143-157, Routledge, Abingdon, UK, 2010.

[27] M. Avanza, "The Northern League and its "innocuous" xhenophobia," in Italy Today The Sick Man of Europe, A. Mammone and G. A. Veltri, Eds., pp. 131-142, Routledge, Abingdon, UK, 2010.

[28] A. Tchouncha, "La comunità senegalese di Torino e dintorni," http://www.provincia.torino.gov.it/xatlante/mediaecomunita/ scheda_senegal.htm.

[29] International Society of Ethnobiology., "International Society of Ethnobiology Code of Ethics," 2008, http://ethnobiology .net/code-of-ethics/.

[30] S. M. U. Brunken, S. Dressler, T. Janssen, A. Thiombiano, and G. Zizka, "West African Plants-A Photo Guide," 2008.

[31] IPNI, "International Plant Names Index," 2011.

[32] P. F. Stevens, "Angiosperm Phylogeny Website," 2001.

[33] The Angiosperm Phylogeny Group, "An update of the Angiosperm Phylogeny Group classification for the orders and families of flowering plants: APG III," Botanical Journal of the Linnean Society, vol. 161, no. 2, pp. 105-121, 2009.

[34] J. Kerharo and J.-G. Adam, "La pharmacopee senegalaise traditionnelle: plantes medicinales et toxiques," Paris, Vigot, 1974.

[35] J. Kerharo, "La médecine et la pharmacopée traditionnelles sénégalaises,” Études Médicales, vol. 1, pp. 7-54, 1975.

[36] J. Kerharo, "La Pharmacopée sénégalaise: catalogue des plantes médicinales et toxiques des Wolof et des Sérer, augmenté de la mention des Noms vulgaires et vernaculaires, des Propriétés et des Utilisations, généralment reconnues en médicine traditionnelle," Annales Pharmaceutiques Française, vol. 25, pp. 385-438, 1967.

[37] P. Bruschi, M. Morganti, M. Mancini, and M. A. Signorini, "Traditional healers and laypeople: a qualitative and quantitative approach to local knowledge on medicinal plants in Muda (Mozambique)," Journal of Ethnopharmacology, vol. 138, pp. 543-563, 2011.

[38] T. A. Osbaldeston and R. P. A. Wood, Dioscorides De Materia Medica: Being an Herbal with Many other Medicinal Materials Written in Greek in the First Century of the Common Era; A New Indexed Version in Modern English, IBIDIS Press, Johannesburg, South Africa, 2000.

[39] A. Pieroni and M. E. Giusti, "Alpine ethnobotany in Italy: traditional knowledge of gastronomic and medicinal plants among the Occitans of the upper Varaita valley, Piedmont," Journal of Ethnobiology and Ethnomedicine, vol. 5, article 32, 2009. 


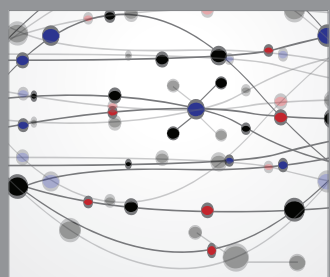

The Scientific World Journal
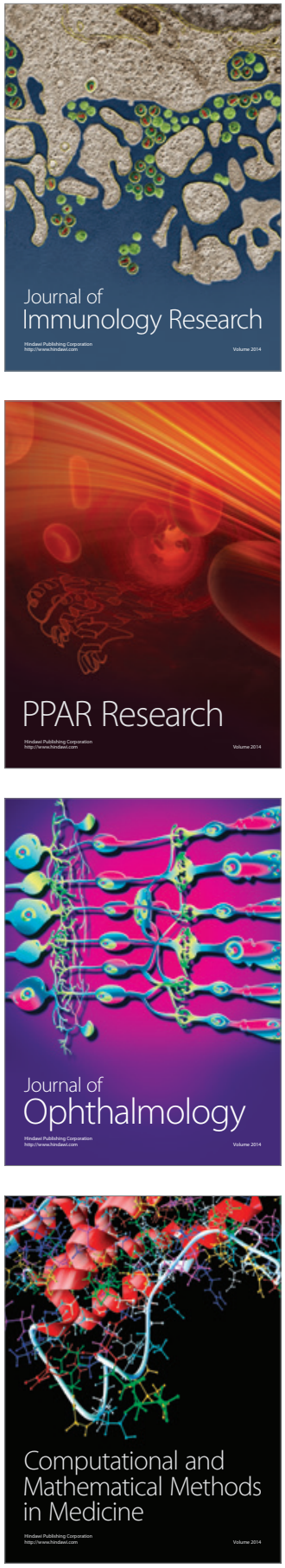

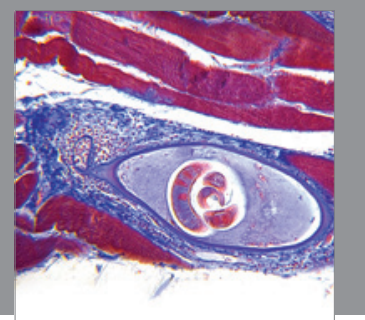

Gastroenterology

Research and Practice
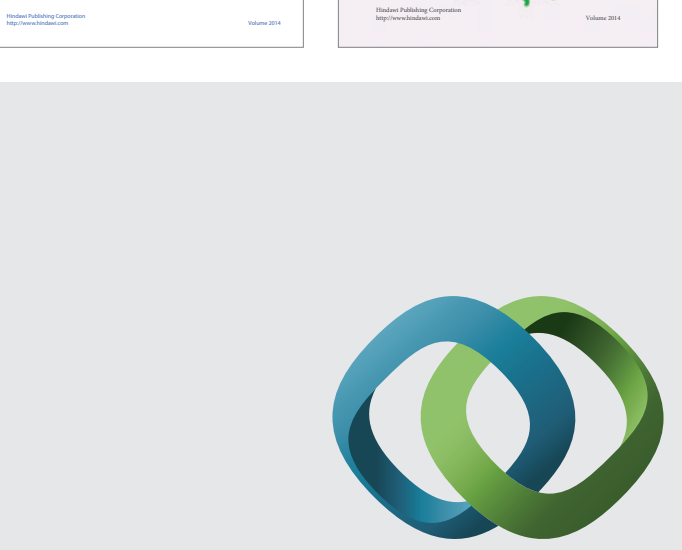

\section{Hindawi}

Submit your manuscripts at

http://www.hindawi.com
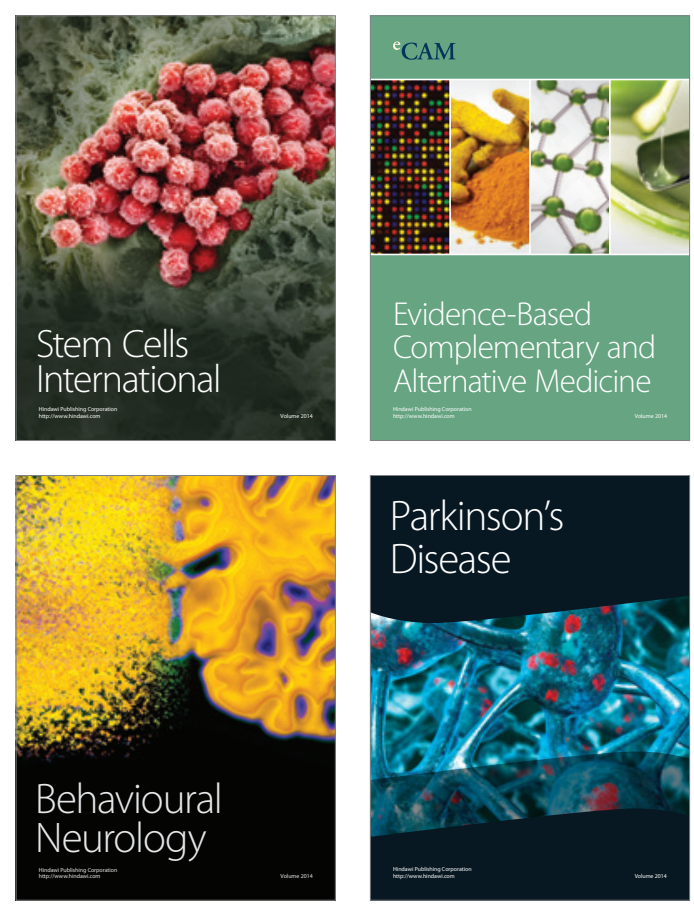

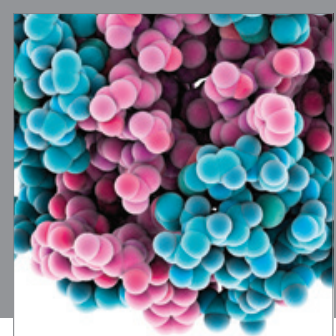

Journal of
Diabetes Research

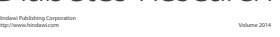

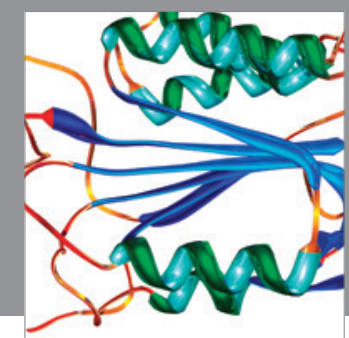

Disease Markers
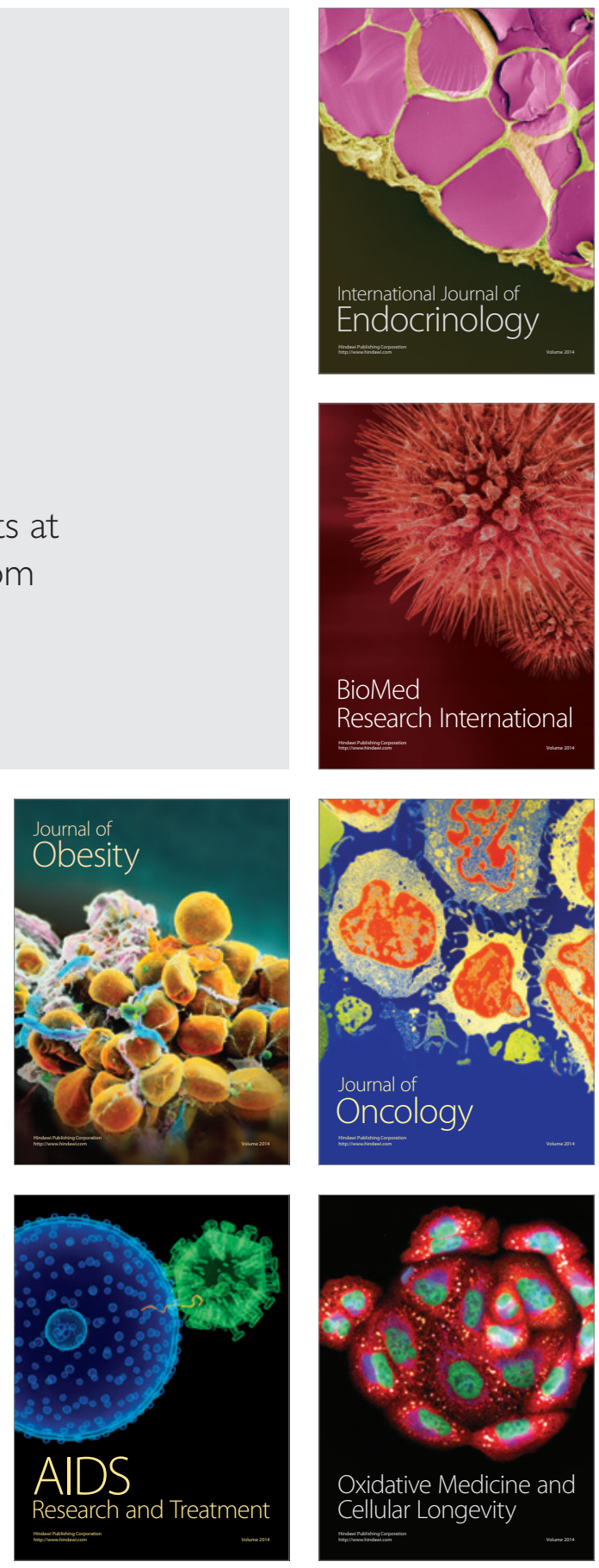